\title{
A COMPARISON OF CRUSHING PARAMETERS OF GRAPHITE COMPOSITE THIN- \\ WALLED CYLINDERS CURED IN LOW AND HIGH PRESSURES
}

\author{
A Thesis \\ Presented to \\ The Faculty of California Polytechnic State University, \\ San Luis Obispo
}

\author{
In Partial Fulfillment \\ Of the Requirements for the Degree \\ Master of Science in Aerospace Engineering
}

By

Trenton John Matson

September 2019 
(C)2019

Trenton John Matson

ALL RIGHTS RESERVED 


\section{COMMITTEE MEMBERSHIP}

TITLE: A Comparison of Crushing Parameters of

Graphite Composite Thin-Walled Cylinders

Cured in Low and High Pressures

AUTHOR: $\quad$ Trenton John Matson

DATE SUBMITTED: $\quad$ September 2019

COMMITTEE CHAIR: $\quad$ Faysal Kolkailah, Ph.D.

Professor of Aerospace Engineering

COMMITTEE MEMBER: $\quad$ Eltahry Elghandour, Ph.D.

Associate Professor of Mechanical Engineering

COMMITTE MEMBER: Dianne DeTurris, Ph.D.

Professor of Aerospace Engineering

COMMITTEE MEMBER: $\quad$ Garrett Hall, Ph.D.

Professor of Civil and Environmental

Engineering 


\begin{abstract}
A Comparison of Crushing Parameters of Graphite Composite Thin-Walled Cylinders Cured in Low and High Pressures

Trenton John Matson
\end{abstract}

Out-of-Autoclave (OoA) processes for manufacturing aerospace-grade parts needs to be better understood to further the development and success of industries that are manufacturing reusable launch vehicles, military and commercial aircraft, and spacecraft. Overcoming the performance limitations associated with OoA, also known as low-pressure prepreg curing, methods (void count, energy absorption, etc.) will help decrease the costs associated with aerospace composite manufacturing and the negative environmental effects correlated with highpressure composite curing methods. Experimental, theoretical, and numerical approaches are used to explore both low and high-pressure curing cycles and how the two different processes affect final cured parts. Quasi-static uniaxial compression tests on 33mm diameter tubular specimens concluded that the high-pressure curing methods (up to 90 psi) increased the likelihood of a final part with increased stiffness compared to the lower atmospheric-pressure methods (14.7 psi) on an order of $22 \%$. After further extension and deformation past the linear elastic region, tests concluded that although the autoclaved specimens may have been higherquality parts, the low-pressure-cured specimens performed more efficiently with respect to energy absorption. Considering the specific energy absorption (SEA) and crush force efficiency (CFE) are both on average around 6\% higher for the low-pressure specimens, it is concluded that they can perform similarly to the high-pressure specimens and possibly even more efficiently depending on the loading conditions and desired purpose of the structure. 


\section{ACKNOWLEDGMENTS}

Thanks to:

- Faysal, for your wisdom, expertise, and effort guiding me through my research.

- My thesis committee, for the invaluable guidance and assistance throughout every aspect of my Thesis project. A special thank you to Dr. Garrett Hall for accepting a last-minute position on my committee after a former member became unavailable.

- Thomas, Tracy, and Taylor Matson, for continually showering me with love, motivation, and support during my college experience.

- Cody Thompson, Josh Dimaggio, and Greg Ritter, for the day-to-day assistance with various obstacles I eventually overcame during my specimen fabrication process.

- Sean Day, for peer support and assistance with ABAQUS software troubleshooting.

- Mechanical Engineering Department Composite Lab, for providing all the resources necessary to fabricate composite thin-walled cylinders. 


\section{TABLE OF CONTENTS}

\section{Page}

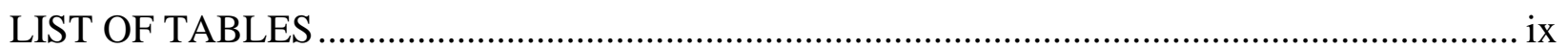

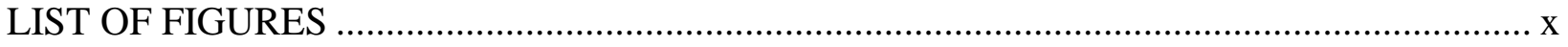

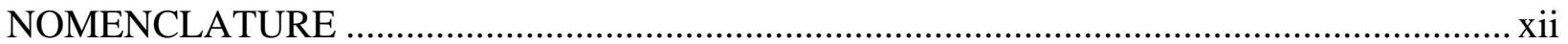

\section{CHAPTER}

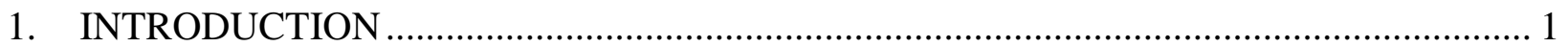

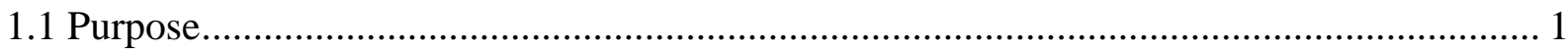

1.2 Previous Studies on OoA Composite Manufacturing ............................................... 2

1.3 Comparison of OoA and Autoclave Prepreg Manufacturing ......................................... 6

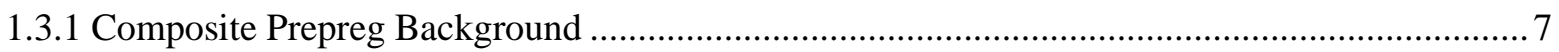

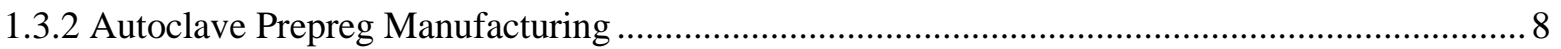

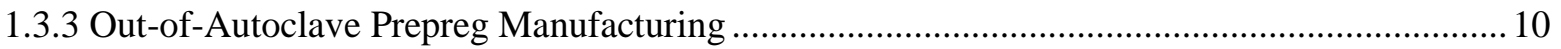

2. EXPERIMENTAL TEST SETUP AND PROCEDURE................................................... 13

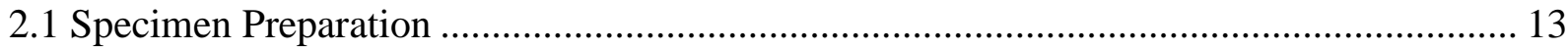

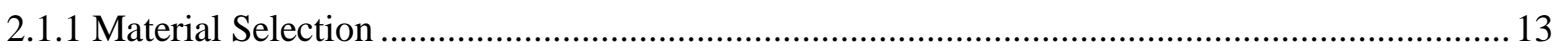

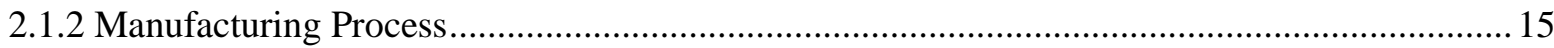

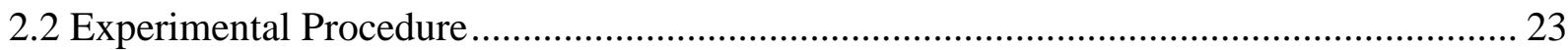

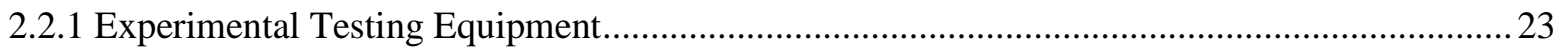

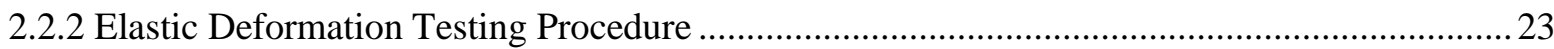

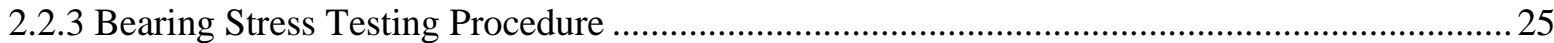




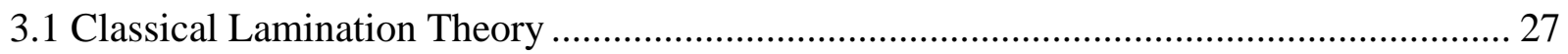

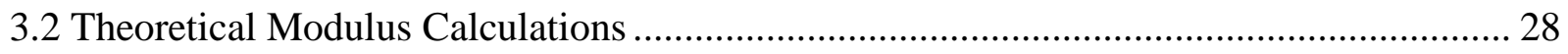

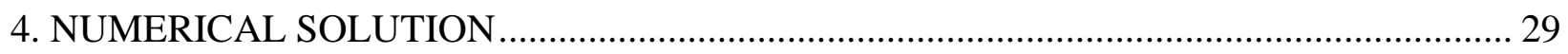

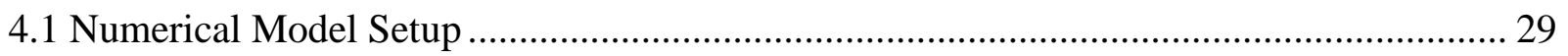

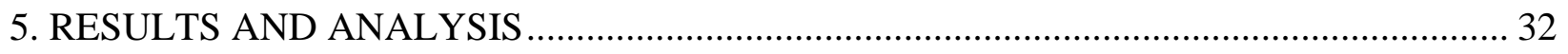

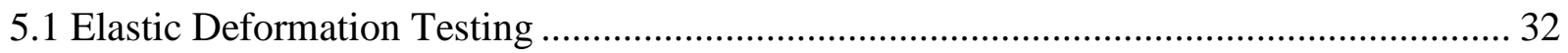

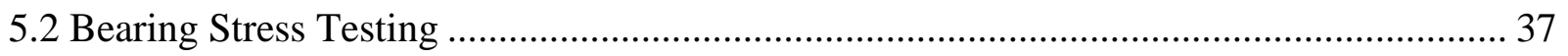

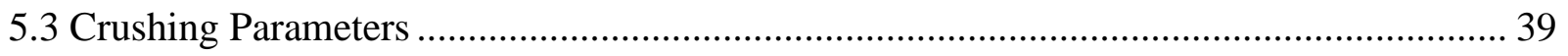

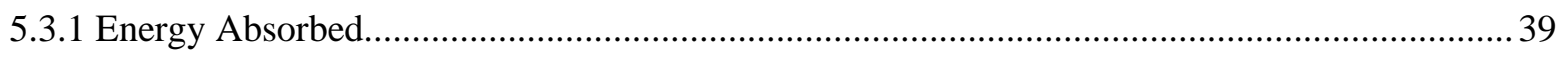

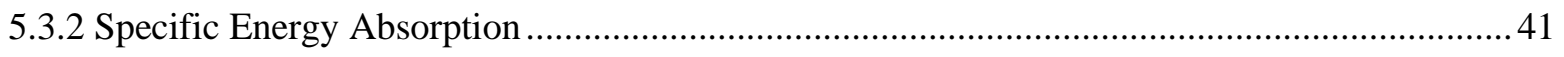

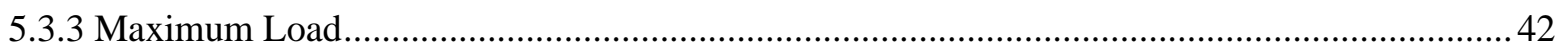

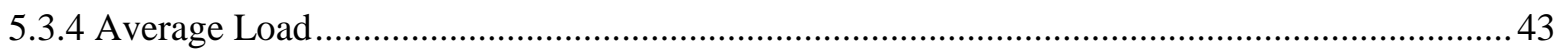

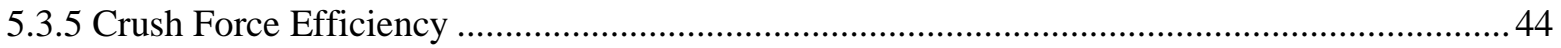

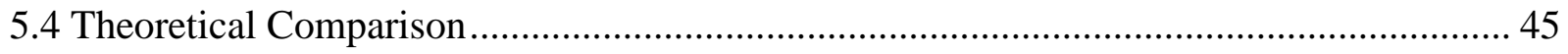

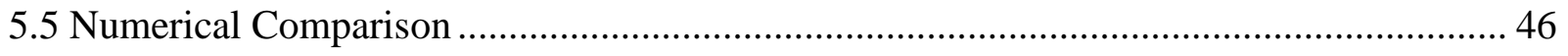

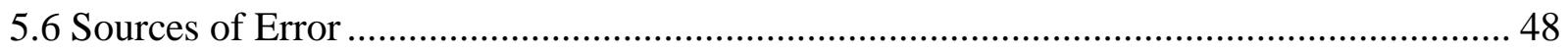

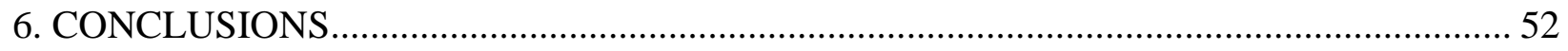

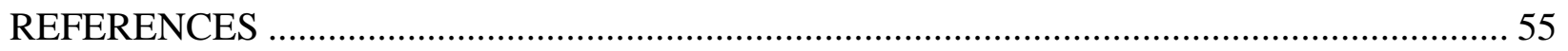




\section{APPENDICES}

A. Stress-Strain Plots from Elastic Deformation Testing ............................................... 58

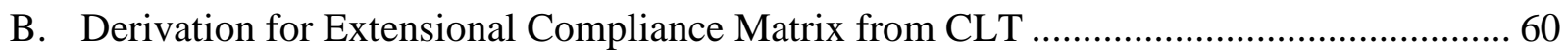

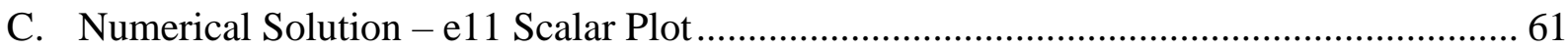




\section{LIST OF TABLES}

Table

Page

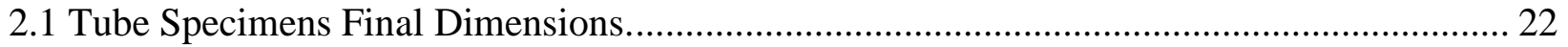

5.1 Final Measured $E_{11}$ Values for All Tube Specimens from Elastic Deformation Testing....... 33

5.2 Final Measured $E_{22}$ Values for All Tube Specimens from Elastic Deformation Testing....... 37

5.4 Comparison of the Experimental and Numerical e11 Values.......................................... 48 


\section{LIST OF FIGURES}

Figure

1.1 A Carbon Fiber UD Tape Manufactured by ZOLTEK..................................................8

1.2 World's Largest Autoclave Built by ASC Process Systems [16] .....................................

1.3 EVaC's in an OoA Composite Prepreg [17]............................................................11

2.1 Aluminum Mandrel Design Drawing. ....................................................................

2.2 PVA Release Agent Curing Technique ................................................................... 16

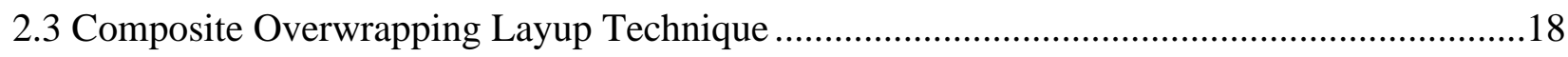

2.4 (Top) Tube Specimen Vacuum Bagging Method. (Bottom) Tube Specimen Hanging

Cure Method in Both the Oven (Left) and the Autoclave (Right.) .....................................19

2.5 Tube Specimen Oven Cure Cycle (Left.) Tube Specimen Autoclave Cure Cycle (Right.) .....20

2.6 Final Cured Tube (Left.) Final Cured Tube Specimens (Right.) .......................................21

2.7 Coordinate Systems Used to Designate Tube Specimen Directions. ..................................22

2.8 Elastic Deformation Experimental Testing Setup.....................................................25

4.1 Meshed Tube Model for the Numerical Solution ...........................................................30

5.1 Linear Elastic Stress-Strain Curve Measured During Elastic Deformation Testing................33

5.2 Bar Graph Representation of the Comparison of Measured E11 Values Gathered from

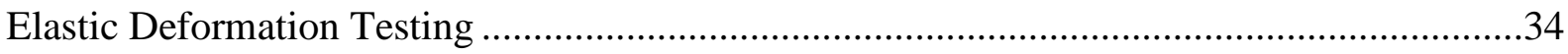

5.3 An Example of the Transformed Strain Components Calculated from Data Gathered

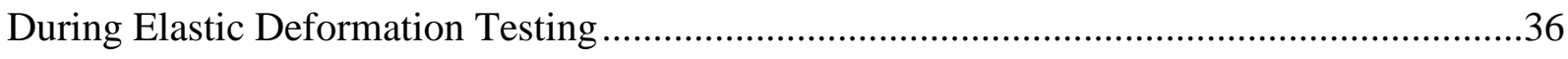

5.4 Deformation Mode of the Tube Specimens Recorded from a Time-Lapse Video During

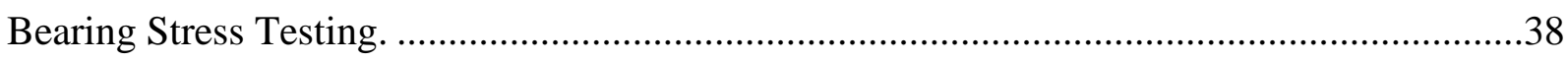


5.5 A Annotated Load-Extension Plot from Plastic Deformation Testing to Show the Different Regions Observed During Bearing Stress Testing.

5.6 Bar Graph Representation of the Comparison of Calculated EA Values Gathered From

Bearing Stress Testing

5.7 Bar Graph Representation of the Comparison of Calculated SEA Values Gathered from

Bearing Stress Testing .41

5.8 Bar Graph Representation of the Comparison of Measured Maximum Loads Observed

During Bearing Stress Testing.....

5.9 Bar Graph Representation of the Comparison of Measured Average Loads Observed

During Bearing Stress Testing.....

5.10 Bar Graph Representation of the Comparison of Calculated CFE Values Gathered from Bearing Stress Testing.

5.11 Wrinkles Formed in the Final Tubes During the Curing Process

5.12 Uneven Contact Surfaces on the Top Edge of Tube 7 Observed During Elastic

Deformation Testing 
NOMENCLATURE

\section{$\underline{\text { English Symbols }}$}

A*-Extensional Compliance Matrix

A - Cross-Sectional Area $\left[\mathrm{mm}^{2}\right]$

D - Diameter $[\mathrm{mm}]$

$\mathrm{E}_{11}$ - Elastic Modulus in the $0^{\circ}$ Tube Direction [GPa]

$\mathrm{E}_{22}$ - Elastic Modulus in the $90^{\circ}$ Tube Direction [GPa]

e11 - Strain in the $0^{\circ}$ Tube Direction $[\mathrm{mm} / \mathrm{mm}]$

$\mathrm{h}-$ Ply Thickness [mm]

I - Area Moment of Inertia $\left[\mathrm{mm}^{4}\right]$

1 or $\mathrm{L}$ - Length [mm]

$\mathrm{m}-$ Specimen Mass $[\mathrm{g}]$

OD - Outside Diameter [mm]

$\mathrm{P}-\operatorname{Load}[\mathrm{N}]$

Q - Reduced Stiffness Matrix

$\bar{Q}$ - Lamina Stiffness Matrix

$\mathrm{t}$ - Thickness [mm]

\section{Greek Symbols}

$\gamma-$ Shear Strain $[\mathrm{mm} / \mathrm{mm}]$

$\gamma^{\prime}$ - Transformed Shear Strain $[\mathrm{mm} / \mathrm{mm}]$

$\varepsilon-$ Strain $[\mathrm{mm} / \mathrm{mm}]$ 
$\varepsilon^{\prime}$ - Transformed Strain $[\mathrm{mm} / \mathrm{mm}]$

$\theta$ - Transformation Angle [degrees]

$v$ - Poisson's Ratio

$\sigma-$ Stress $[\mathrm{Pa}]$

$\tau$ - Shear Stress $[\mathrm{Pa}]$

\section{$\underline{\text { Acronyms }}$}

BC - Boundary Condition

CAD - Computer-Aided Design

CFE - Crush Force Efficiency

CFRP - Carbon Fiber Reinforced Polymer

CLC - Combined Loading Compression

CLT - Classical Lamination Theory

CTE - Coefficient of Thermal Expansion

DAQ - Data Acquisition

DOC - Degree of cure

DOF - Degrees of Freedom

EA - Energy Absorbed [kJ]

EVaC - engineered vacuum channels

G10 - A High-Pressure Fiberglass Resin-based Laminate

KE - Kinetic Energy

OHC - Open-Hole Compression

OL - Outlife 
OoA - Out of autoclave

PVA - Polyvinyl Alcohol

SBS - Short Beam Shear

SEA - Specific Energy Absorption [J/kg]

$\mathrm{Tg}-$ Glass transition temperature

UD - Unidirectional

UTS - Ultimate Tensile Strength [MPa]

Wt\% - Weight Percentage

\section{$\underline{\text { Definitions }}$}

Angle-Ply - A laminate that all the plies are the same thickness and material and are oriented at $+\theta$ and $-\theta$. An angle-ply laminate can consist of $0^{\circ}$ and $90^{\circ}$ plies but usually incorporates other angles in its construction

B-stage - describes a partially-cured state for a one component epoxy system generally used in thermosetting prepregs

Cold-flow - a form of mechanical creep that can happen in thermosetting resins during debulk

Creep - the tendency of a solid material to deform permanently under the influence of persistent mechanical stresses

Cross-Ply - A laminate that consists completely of only $0^{\circ}$ and $90^{\circ}$ plies 
Debulk - a method to reduce the air trapped in between plies during a layup that utilizes drawing a vacuum on the pre-cured layup

Fiber volume ratio - percentage of fiber volume in the entire volume of prepreg

Laminate - an organized stack of unidirectional composite plies that is defined by the stacking sequence, which indicates the directions of each ply

Peel ply - synthetic cloth that is draped over an epoxied surface as a release layer, also doubles as an air-evacuation channel

Thermoset - a type of epoxy resin used in prepregs that employs an epoxy resin in the B-stage

Wet layup - a form of composites manufacturing that involves the layering of reinforcing fibers with a liquid resin system to create a laminate 


\section{INTRODUCTION}

Autoclaves are used in the composite prepreg manufacturing process to create essentially void-free parts that are structurally capable of being aerospace primary structures; however, they have the drawback of being inherently small and expensive to install and operate. To help continue the privatization of the aerospace industry by allowing smaller startup companies to manufacture aerospace-grade parts at reduced costs, the knowledge of OoA composite prepreg manufacturing needs to be expanded.

This document explores the necessary techniques to create aerospace-grade composite parts without the increased compaction pressure utilized in an autoclave and compares the mechanical responses of parts that are cured in both low and high pressures.

\subsection{Purpose}

The goal of this study is to explore the two most common curing methods for composite prepregs and to conduct an experiment to compare and quantify the mechanical responses of parts cured with each method under compressive loading. This study will expand on previous work [1] which showed that autoclaved prepreg is generally stiffer than OoA prepreg. This previous study conducted by Kellas et al. tested sandwich panels mostly under tensile loading and had a focus on mechanical responses in different environmental conditions. This current study will dive deeper into the crushing parameters and compressive deformation modes between the two test conditions in similar environmental conditions to emphasize the comparison between curing methods rather than the changes brought upon by environmental effects. Also, this study will branch out to investigate the mechanical responses with both numerical and theoretical solutions. Several things need to be completed to perform this study. First, research needs to be 
conducted to help choose the most appropriate material and ply orientation to investigate. Further research will be performed to achieve adequate knowledge about manufacturing techniques to assure the specimens will be realistic test subjects for the scope of this research. Next, the graphite composite thin-walled cylinders will need to be laid up and cured appropriately before testing and analysis can begin. Rosette strain gauges will be carefully adhered to the specimen to allow for accurate strain data to be collected. Finally, the specimens will be subjected to quasistatic compressive loading and the experimental results will be compared with the numerical and theoretical solutions. In summary, the goals of this current study are to:

1. Investigate and explore the manufacturing techniques needed to create composite prepreg parts cured both in and out-of-autoclave.

2. Design, fabricate, and test graphite composite thin-walled cylinders.

3. Compare numerical and theoretical solutions with experimental results.

4. Expand upon previous work to quantify a comparison of mechanical responses between the two curing methods.

\subsection{Previous Studies on OoA Composite Manufacturing}

The difficulty of achieving autoclave-quality parts ( $<1 \%$ void content) with OoA processing techniques is widely accepted [2]. Kourkoutsaki et al. asserted that the main physical mechanism for void formation in prepregs is the mass transfer of entrapped species, including air, moisture, and other volatiles, out of the compacted laminates before they are cured [3]. Also, Hughes, Hubert, Kay, and Fernlund all agreed on the assertion that void content increases with part size. Using the Darcy Flow Equation relating fluid flow to pressure losses along a given length, a model was produced to approximate the time needed to evacuate trapped air molecules 
out of inter-laminar spaces in prepreg stacks. It was found that time scales of the main gas transport processes involved in void formation scale quadratically with part length $[4,5]$. It is predicted that heavy-lift launch vehicle fuselages will be the largest composite structures that will need to be fabricated for the aerospace industry, which need to be manufactured as one contiguous structure to meet acceptable mechanical performance standards. As discussed by Sutter et al. prepreg out-life (OL) negatively effects OoA prepregs more extremely than conventional prepregs [6]. Considering the fabrication of larger launch vehicle structures involves longer OL periods for materials and larger part sizes, it is evident that with current OoA processing technology such structures will be manufactured with more voids than conventional methods.

With the widespread knowledge that they are more susceptible to developing voids, OoA prepreg systems are designed slightly differently than conventional prepregs. The main difference between the two systems is that OoA prepregs have dry fibrous channels distributed throughout the resin matrix, making them "no-bleed systems" [7]. To promote adequate vacuum distribution and ensure there are sufficient air pathways for mass transfer of entrapped species, OoA prepregs are only partially impregnated with resin. Partial impregnation allows the prepreg to be cured at lower temperatures and pressures but increases the possibility of inadequate resin saturation during cure. Edge-breathing, or the use of permeable dams, is used to further promote air evacuation and fiber impregnation [4]. The impregnation of the prepreg completes during the cure cycle and is solely driven by the differential between atmospheric pressure and the absolute pressure available during cure, which is about 14 psi (hard vacuum) for OoA. Kay et al. also explored the effect that moisture content in the laminate had on the final part. It was found that dissolved moisture is a significant source of voids in OoA prepregs with high moisture content 
because it drastically increases the amount of gas that needs to be evacuated from the layup. Recalling their model based on the Darcy Flow equation, conclusions suggest that longer room temperature debulks will help to evacuate interlaminar air pockets that will eventually produce voids during the cure process [5]; however, a competing theory put forth by Ridgard et al. suggests that long vacuum cycles at room temperature will induce cold flow of the resin $[3,8]$. Cold flow of the resin prior to cure is undesirable because it increases the probability that air pathways for entrapped species to escape the laminate will be closed.

The mechanical performance of large launch vehicle sandwich panels cured in high and low pressures was investigated under tensile loading by Kellas et al., and they found that at elevated temperatures, the OoA specimens were on average 10\% stronger and more compliant than the autoclaved specimens. The autoclaved specimens were on average $2 \%$ stiffer than the OoA specimens. At room temperature, the differences in Modulus and uniaxial tensile strength (UTS) were negligible between the two types of panels, despite the evidence of increased manufacturing defects in the OoA specimens [1]. Dang et al. investigated the differences in mechanical responses between low pressure and high pressure open-hole compression (OHC), combined loading compression (CLC), short beam shear (SBS), and tensile specimens. The two specimens were observed to be chemically different, but they were mechanically comparable to each other through the entirety of experimental testing. The glass transition temperature ( $\mathrm{Tg}$ ) and resin content (wt\%) were both consistently lower in the OoA specimens, but the laminate qualities were deemed acceptable with respect to ply wrinkling, voids, and resin pooling [2].

With respect to energy absorbing (EA) structures, tubes are generally chosen as an adequate experimental specimen geometry due to the fabrication ease, close resemblance to crashworthy structures, and breadth of prior research conducted on them [9]. The primary 
objective of an EA structure is to absorb the kinetic energy (KE) of loading through dissipative mechanisms, such as material failure, in a controlled manner. Composites have been shown to have a significantly higher specific energy absorption than metallic alloys, but the issue with composite EA structures is that the device must crush in a controlled manner [10]. Unlike metallic structures, the crushing behavior of carbon-fiber-reinforced-polymeric (CFRP) structures are dominated by the development of fracture, interlaminar delaminations, and extensive micro-cracking, which can be unpredictable. Zhu et al. investigated the crushing characteristics of different configurations of metal, composite, and metal-composite hybrid tubes. Their research concluded that the crushing process of a CFRP tube in the post-elastic stage of compression was much more stable than the aluminum or hybrid counterparts, especially those with circular cross-sections. The failure of CFRP tubes under axial compression were generally observed in three modes: progressive end-crushing, unstable local tube wall buckling, and mid-length collapse. The most desirable mode being the first, progressive end-crushing [11]. Farley et al. found that the SEA of graphite/epoxy tubes increases with the reduction of the diameter-over-thickness (D/t) ratio. In other words, the SEA of a CFRP tube can be increased by adding more layups (increasing wall thickness) to a certain extent [12]. This assertion was supported by experiments conducted by Hou et al. when they found that for a constant diameter, SEA increases directly with wall thickness up to a critical value $(\mathrm{D} / \mathrm{t}<15)$, where it begins to decrease [10]. Zhang et al. concluded that the stacking sequence and fiber orientation of a CFRP tube also have strong influences on the deformation of the structure in the post-crushing stage [13].

Although studies on material and geometrical optimization of EA capability of axially crushed circular composite tubes are still insufficient and not well understood, it is widely 
accepted that the crushing behavior of a circular CFRP tube can be tailored through structural design parameters, such as fiber orientation. Mahdi et al. concluded that angle-ply, more specifically $\left[15 \%-75^{\circ}\right]$ and $\left[75 \%-15^{\circ}\right]$, CFRP tubes possessed higher load-carrying capacities and yielded higher initial loads than the cross-ply counterparts. However, the high load capacity lead to more unstable and catastrophic failure mechanisms than the cross-ply tubes [14]. On the contrary to these findings, Thornton et al., agreeing with Zhang et al., found that in the stable post-elastic collapse region, tubes fabricated with a $\left[0 \% 90^{\circ}\right]$ stacking sequence had consistently higher SEA values than tubes fabricated with a [45\%-45] stacking sequence [13].

\subsection{Comparison of OoA and Autoclave Prepreg Manufacturing}

With current knowledge of OoA processing techniques, it is hard to consistently achieve

the $<1 \%$ autoclave quality void content required for aerospace primary structures, which include but are not limited to wings, fuselages, launch vehicle landing struts, and cryogenic fuel tanks. Composite structures for heavy-lift launch vehicles are projected to be the largest sustained composite structures ever fabricated in the aerospace industry. Considering the current limited access to autoclaves large enough to process composite shells with a 9-10-meter diameter, NASA conducted a study to estimate the cost associated with building a 40'x $80^{\prime}$ autoclave large enough to cure 10 -meter diameter launch vehicles. The study resulted in a $\$ 40 \mathrm{M}$ price tag to build the autoclave, and an additional $\$ 60 \mathrm{M}$ solely in installation fees [6]. To continue the privatization of the reusable launch vehicle manufacturing industry, an emphasis on the research and development of OoA processing standards is necessary. Even the Department of Defense acknowledged that future military aircraft programs will be produced in small volumes with smaller budgets, which can be assumed will be true to a much further extent for NASA programs 
[8]. This project will analyze the comparison of crushing performance between OoA and autoclaved specimens to determine if there is any discrepancy in mechanical properties between the two curing methods.

\subsubsection{Composite Prepreg Background}

Advanced composite structures can be processed and manufactured in a variety of ways including hand wet layup, filament winding, resin infusion processes, and hand prepreg layup. Composite prepregs are fibers that are pre-impregnated with an epoxy resin in the B-stage that can be cured at room temperature, in an autoclave, or in a conventional oven. Prepreg has become a very popular method of fabricating composite structures in many industries due to the ease of use, low void content in final parts, increased control of laminate thickness, and other benefits. Prepreg composite manufacturing is also desired as compared to wet layup because prepregs are engineered to have the ideal amount and distribution of resin to promote uniform resin distribution throughout the final cured part and because of the increased amount of time available to physically layup the material in a controlled environment. Composite prepregs are generally made as UD tapes and stored in large rolls that can be cut to length and laid up with the longitudinal fibers in different stacking sequences to fabricate laminates designed for different applications [8]. A typical roll of carbon fiber UD prepeg tape is pictured below in Figure 1.1. Composites are widely used in the aerospace industry due to the combination of high strength, stiffness, and lightweight properties. 


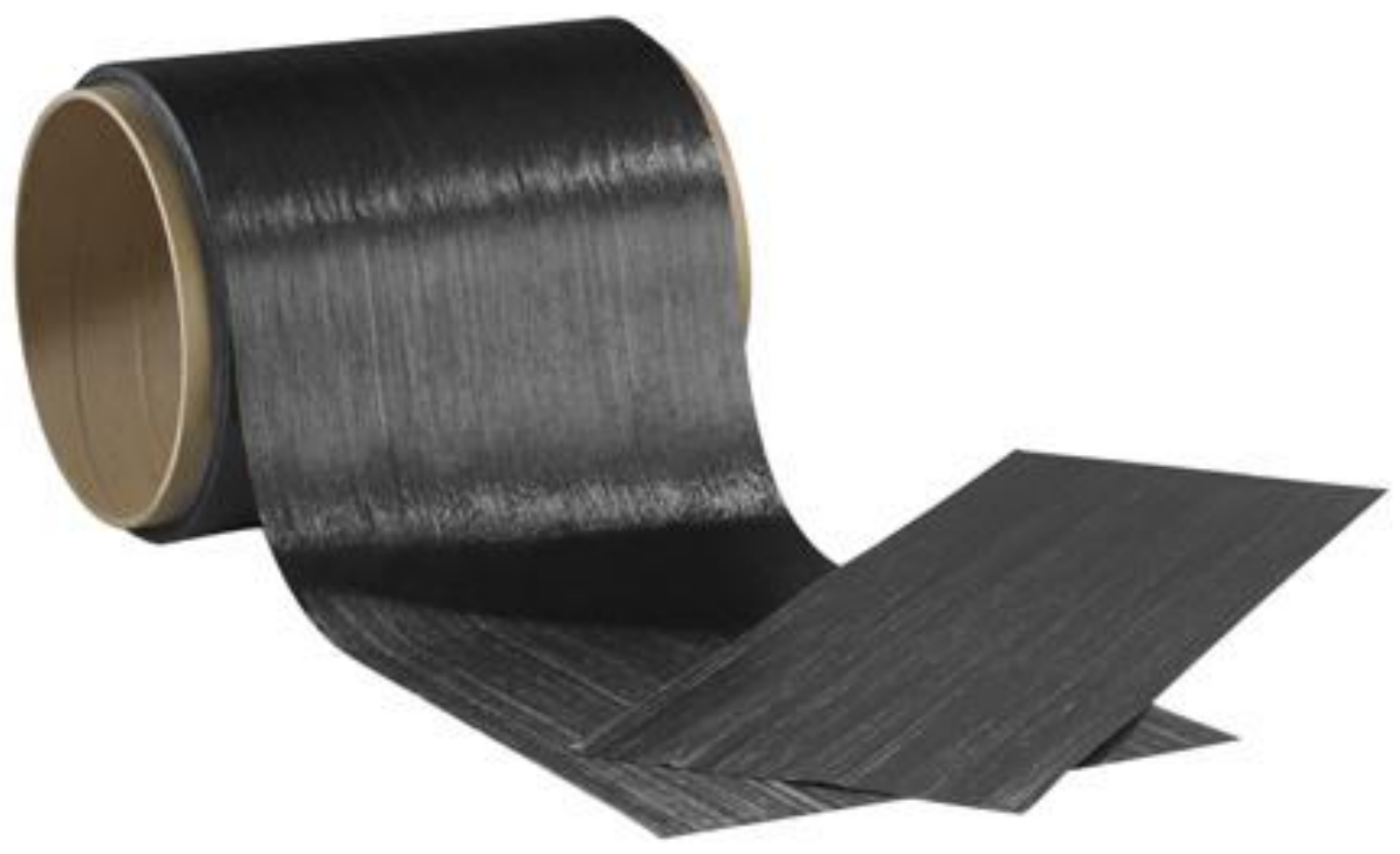

Figure 1.1 A Carbon Fiber Unidirectional (UD) Tape Manufactured by ZOLTEK.

To achieve final part quality, the prepregs need to be exposed to elevated temperatures and pressures that will transform the initially tacky and malleable resin into a stiff and glassy matrix. There are currently two main methods of curing prepregs: in high pressure autoclaves and in low pressure industrial ovens, which is generally referred to as Out-of-Autoclave (OoA).

\subsubsection{Autoclave Prepreg Manufacturing}

The conventional composite prepreg curing method involves the use of an autoclave, which can be described as a pressurized oven (up to $90 \mathrm{psi}$ ) [2]. Autoclave prepreg manufacturing is preferred compared to OoA manufacturing because of the increased pressure that the autoclave can produce on the part during the cure cycle. The pressure helps to "pressout" unwanted volatiles and air bubbles in between the plies of the layup, which directly increases the final quality of the manufactured part [15]. 
Autoclaves are inherently expensive to install, operate, and maintain because they utilize high amounts of water, air, natural gas, nitrogen, and electricity to operate. Also, cured parts are limited to the size of the autoclave, which are generally smaller than an industrial oven. Pictured below in Figure 1.2, the world's largest autoclave was built by ASC Process Systems to help Boeing cure composite fuselage sections for the Boeing 787 Dreamliner passenger aircraft. The project took over 800,000 hours of designing on a supercomputer, cost over $\$ 45$ billion, and took over $1 \frac{1}{2} 2$ years to manufacture [16]. An industrial oven of the same size takes much less time and money to design, manufacture, and operate.

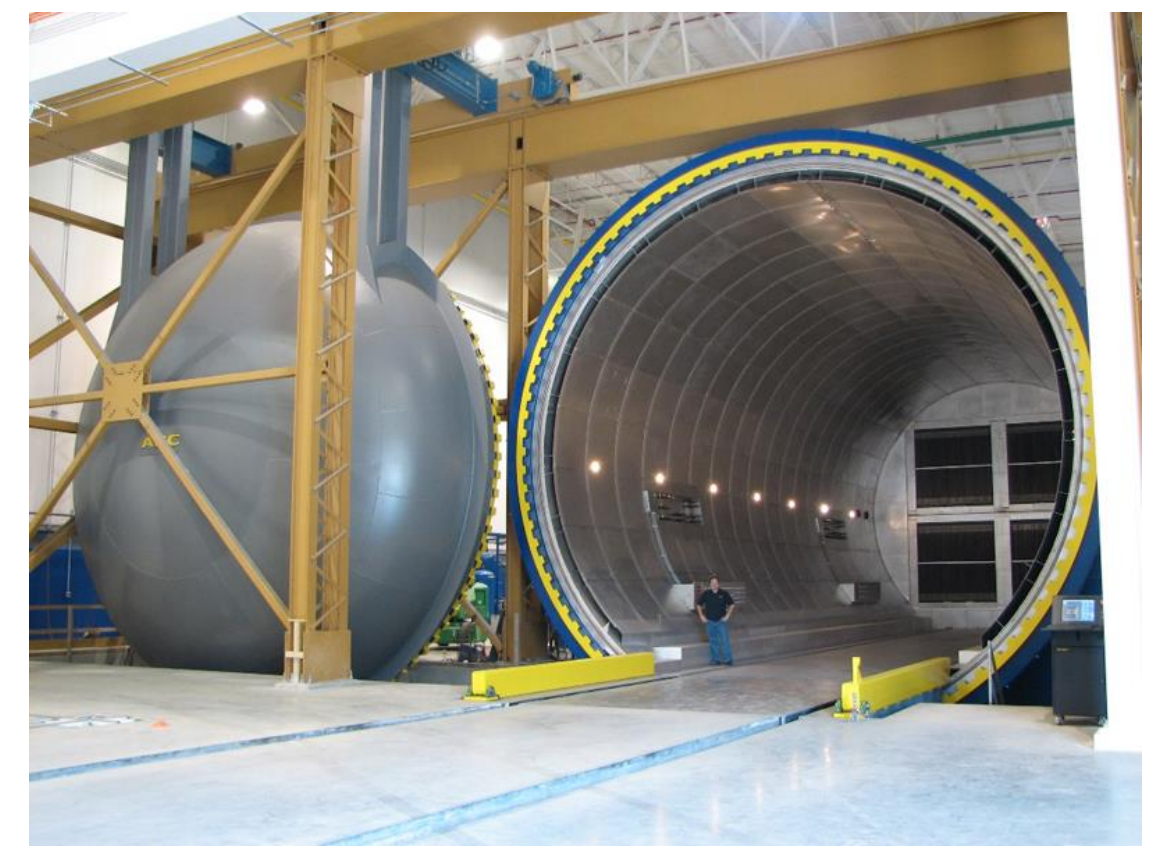

Figure 1.2 World's Largest Autoclave Built by ASC Process Systems [16].

Current and future aerospace companies will need to establish a status quo for manufacturing composites OoA in order to reduce costs and increase manufacturing efficiency. The USAF has identified that OoA prepregs are vital to achieving fast and affordable aircraft 
development programs because of the iterative design nature [8]. A cheaper and more cellular approach to manufacturing composites is necessary to efficiently produce prototypes in small volumes to progress through the design process, and to preserve natural resources when that design reaches the full-scale production phase. In addition to efficiency, current OoA processing methods are incapable of producing aerospace-representative parts with similar quality to those manufactured with conventional processing methods [8].

\subsubsection{Out-of-Autoclave Prepreg Manufacturing}

OoA prepregs are inherently designed and manufactured differently than other prepregs that are designed to be cured in an autoclave. Because air removal is a key requirement for low porosity OoA-cured parts, OoA prepregs are only partially impregnated, less so than autoclave prepregs. OoA prepregs are purposefully manufactured with dry fibers as well as resin-rich areas. Pictured below in Figure 1.3, these dry areas are sometimes denoted as "engineered vacuum channels" (EVaCs), and these channels create a permeable network of pathways throughout the uncured prepreg, which allows vascular air flow throughout the material. During the curing process, the viscosity of the resin decreases which allows for it to move more freely throughout the prepreg, thus impregnating these EVaCs. To promote through-thickness air removal, semi-permeable layers, like peel-ply, are utilized in between the prepreg and the breather cloth during cure. These permeable layers act as release layers as well as all pathways for excess resin to bleed out of the material $[17,18]$. 


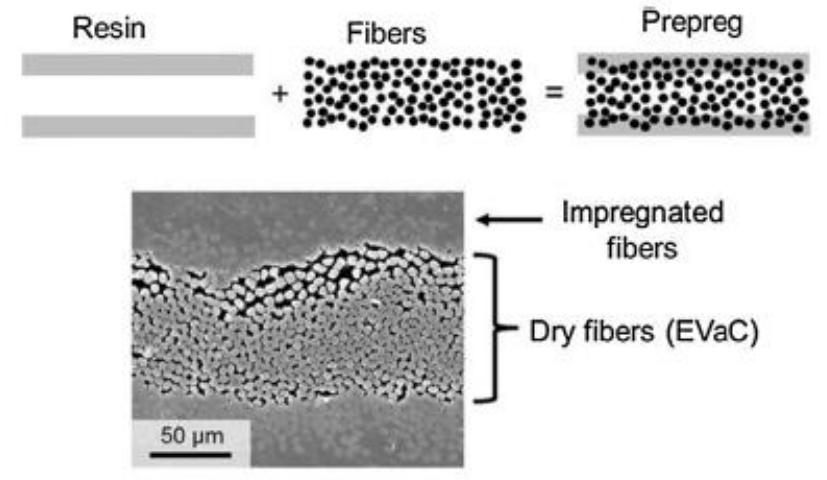

Figure 1.3 EVaC's in an OoA Composite Prepreg [17].

Debulking is a pre-cure compaction procedure used very widely in both conventional and OoA prepreg composite manufacturing. It involves the composite part to be vacuum bagged and compacted under vacuum pressure from anywhere between five minutes and 24 hours, depending on the part size and geometry. Debulk length also depends on the current stage of layup of the part, for example a part that is fully laid up with all the required plies may require a longer debulk time than a part that is in the preliminary layup phase. Although is it used in both conventional and OoA manufacturing, debulking is a much more important factor for OoA prepregs because air evacuation is such a big concern during the OoA manufacturing process. However, debulking for too long can also induce negative effects, such as cold flow. Cold flow is a form of creep, which inhibits itself as a resin slowly moving throughout the fibers within a prepreg. This phenomenon is highly detrimental to OoA prepregs because the thermosetting resin can cold flow into EVaCs, clogging them and restricting the paths for air to be evacuated from the prepreg during cure [3]. Debulking is generally a room-temperature process but can be performed with the application of heat; however, heated-debulks are risky because they can advance the DOC of the prepreg, which alters the chemistry of the material. 
Changing the DOC of a prepreg essentially furthers the crosslinking process past the Bstage, which will in effect change the Tg of the pre-impregnated thermosetting resin. One of the most important chemical characteristics of a prepreg is its $\mathrm{Tg}$, which is essentially the temperature range that a thermosetting resin changes from a rigid state to a more compliant and "rubbery" state. Tg is strongly dependent on cure cycle, and can greatly alter mechanical properties, such as Modulus, CTE, hardness, strength, thermal conductivity, and electrical conductivity. It is important for the resin to reach its Tg during cure because that will ensure a high cross-link density, which is important to ensure the full physical and mechanical potential of an epoxy adhesive $[19,20]$. 


\section{EXPERIMENTAL TEST SETUP AND PROCEDURE}

Thin-walled cylinders were chosen as the test specimens for this Thesis because of the vast amount of research that has already been conducted on them. A mandrel overwrapping technique that is widely used in the composite manufacturing industry was used to manufacture the specimens. This process is generally automated, but due to a lack of resources on campus the tube specimens were laid up and overwrapped by hand in this Thesis. This chapter describes the experimental task involved with this research. Details are provided on the tube specimens manufacturing process, the testing equipment that will be used during experimentation, and the experimental procedure.

\subsection{Specimen Preparation}

The following section will expand on details pertaining to the tube specimens manufacturing process. These details include but are not limited to material selection justification, layup procedures, and prepreg cure cycles. The desired nominal geometric ratios for the tube specimens were chosen from gathered information from the literature review. The L/D ratio was chosen to be 1.5 to inhibit crushing rather than buckling or shearing during experimental testing. The $\mathrm{D} / \mathrm{t}$ ratio was chosen to be 33.33 because it is a very commonly utilized ratio for tube compression testing.

\subsubsection{Material Selection}

For the scope of this project, one material is chosen for both test conditions to reduce the variables between each test. The minimization of variables between test conditions, especially with regards to material selection, is seen as a very important factor considering the range of 
available materials that could have been chosen. Each material available for use on campus at Cal Poly was donated to the school after the expiration date, and many of these dates vary significantly. It is important to note that material OL is also a very large factor relating to part quality and choosing a single material for each test condition eliminates this variable. Also, the exposure to moisture pre-cure is another very significant factor relating to part quality. Prepreg must be stored in temperatures ranging from $0^{\circ}$ and $5 \mathrm{C}$ to prevent premature cross-linking of the molecules in the resin, which essentially stalls the inevitable cure cycle of the impregnated resin. Rolls of prepreg carbon that are exposed to ambient air during storage are more susceptible to the entrapment of frozen water molecules in the pre-impregnated resin, which significantly increases the amount of gas and moisture absorbed by the material through desorption of said resin. The additional absorbed gasses dramatically increase the amount of mass that needs to be evacuated before the material is cured, which directly correlates to longer debulk times. Longer debulks are undesirable for OoA prepregs because the increased time under debulk promotes cold flow of the resin throughout the material, which causes the collapse of EVaCs in the prepreg $[5,7,15]$. The entirety of the available materials at Cal Poly were not sealed and stored appropriately, so a material that was stored adequately was chosen to increase the correlation of this research to industry standards.

TC 275_1/HM63 12k UD tape, a OoA prepreg manufactured by TenCate Advanced Composites, was chosen to manufacture both the OoA specimens and the autoclaved specimens because autoclave prepregs do not have sufficient EvaCs to inhibit adequate gas transport throughout the material during the early processing stages. The stacking sequence of the layup for the tube specimens was chosen to be $\left[\left(0 / 90^{\circ}\right)_{5} / 0^{\circ}\right]$ because cross-ply CFRP tubes have been proven to have good SEA properties, as compared to other angle ply stacking sequences [13]. A 
symmetric and specially orthotropic stacking sequence was originally desired to simplify postprocessing; however, an extra ply with the fibers in the axial direction was used because wrinkling was seen in the tubes that were wrapped last with plies that had fibers in the longitudinal direction. Also, an eleven-ply layup was found to satisfy the desired D/t ratio as closely as possible through the prototyping stage of manufacturing. Some concerns for curing OoA prepregs in an autoclave include but are not limited to inordinate amounts of resin bleedthrough compromising the strength of the part by increasing the fiber volume ratio and high external pressures closing off EvaCs that are essential for adequate gas removal [4,17]. These factors are considered in the sources of error for this experimentation.

\subsubsection{Manufacturing Process}

The tube specimens were fabricated by a roll-wrapping technique over an aluminum mandrel with a 1.25" outer diameter. As seen in Figure 2.1, the aluminum mandrel was machined with a $.25^{\circ} \mathrm{draft}$ angle to promote easier demolding. Before each layup, the mandrel was released with four layers of a polyvinyl alcohol (PVA) release agent that was cured in the sun at ambient temperature. As seen in Figure 2.2, the mandrel was suspended and rotated every two to three minutes to mitigate dripping, uneven drying, and to ensure each layer of release agent was nominally the same thickness. In some cases, the mandrel was bagged and frozen overnight for layup the next morning. 


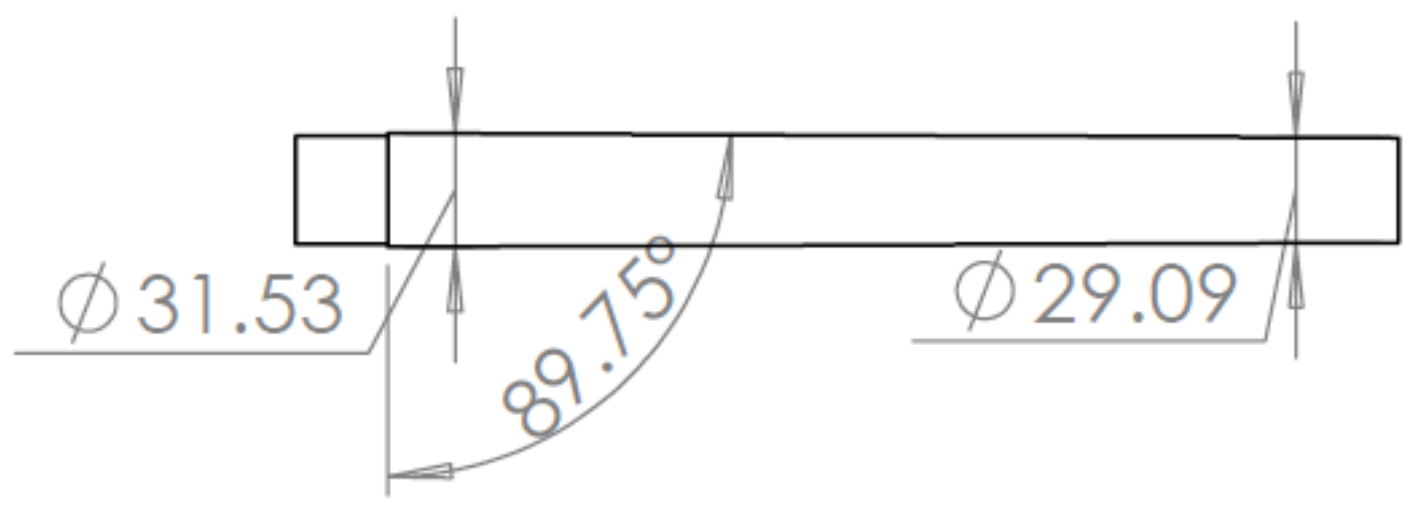

Figure 2.1 Aluminum Mandrel Design Drawing.

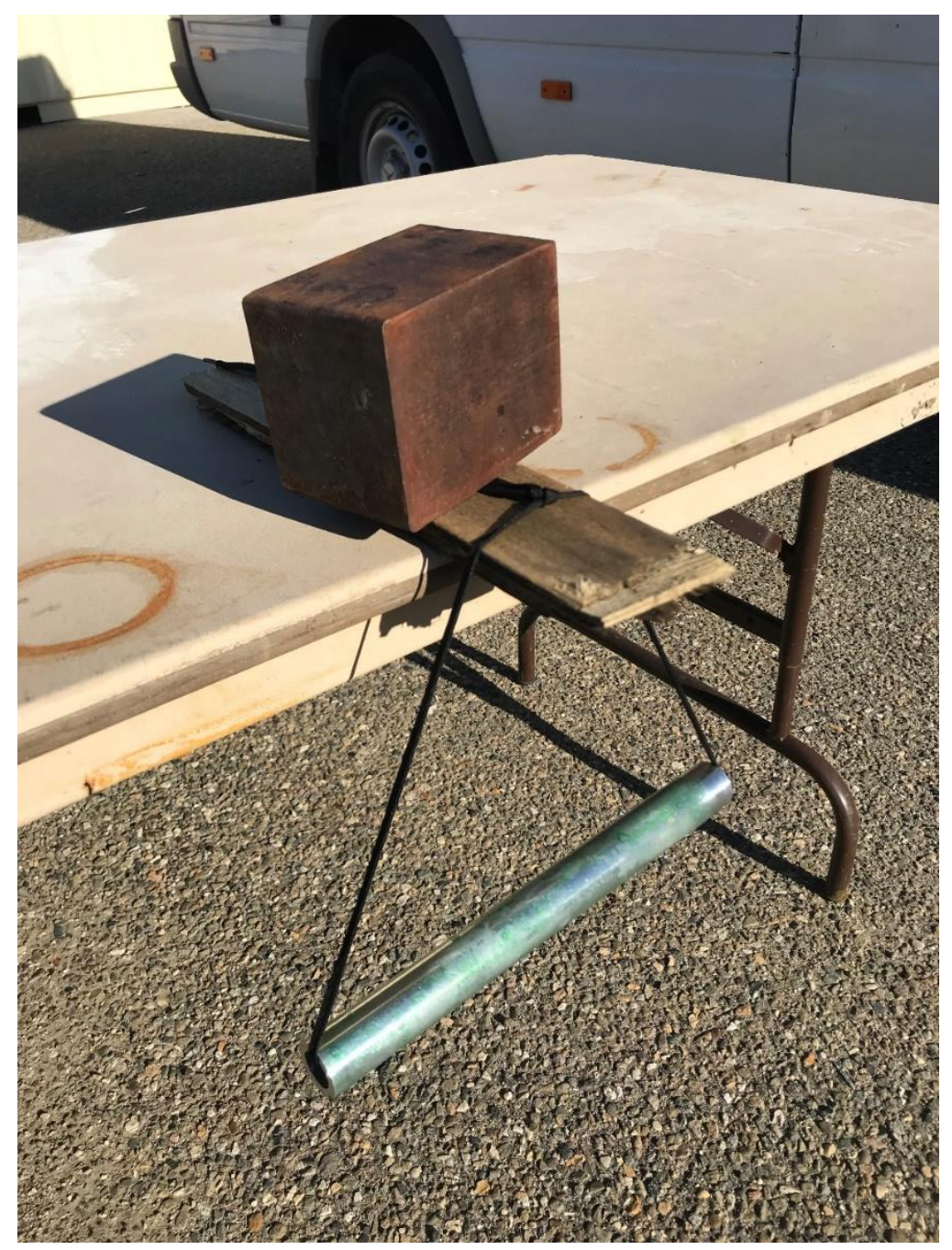

Figure 2.2 PVA Release Agent Curing Technique. 
The Prepreg material was stored in a freezer in the Mechanical Engineering Composite Structures lab at a nominal temperature of $\left(0^{\circ} \mathrm{F}\right)$. Before layup, the roll of material was taken out of the freezer to thaw at room temperature for two hours. After the material reached room temperature, the sealed bag was opened to begin cutting. The prepreg was cut to lengths of nine inches with fiber directions in both the $0^{\circ}$ and $90^{\circ}$ directions. In most cases, the correct number of uncured plies were bagged separately for each respective layup and were stored for layup on a later date.

Before the layup phase, the prepreg material was removed from the oven and thawed to room temperature. After the material reached room temperature, it was vacuum-bagged and debulked for 45 minutes before layup commenced. The baseline debulk time was lowered from the recommended duration of several hours to mitigate the chance of inducing cold flow in the prepreg, and the negative environmental effects because the material had previously accumulated such a long OL.

As pictured in Figure 2.3, the tube layup sequence consisted of each respective ply of the $\left[\left(0^{\circ} / 90^{\circ}\right)_{5} / 0^{\circ}\right]$ layup being rolled onto the mandrel in consecutive order. As seen in the top right of Figure 2.3, the preliminary edge of the prepreg was partially adhered to the mandrel by applying sliding pressure in the direction of the fiber. After the edge was sufficiently adhered to the mandrel, the mandrel was rolled to adhere the remainder of the ply. After all eleven plies were rolled onto the mandrel, Teflon peel-ply was overwrapped onto the prepreg to act both as a release layer and a resin-bleed layer. After the peel-ply, Dunstone HST-20 heat shrink tape was overwrapped onto the peel-ply. The shrink tape was held in tension during application to ensure maximum compaction during cure. High-temperature vacuum sealant tape was used to secure the peel-ply and heat shrink overwraps. 


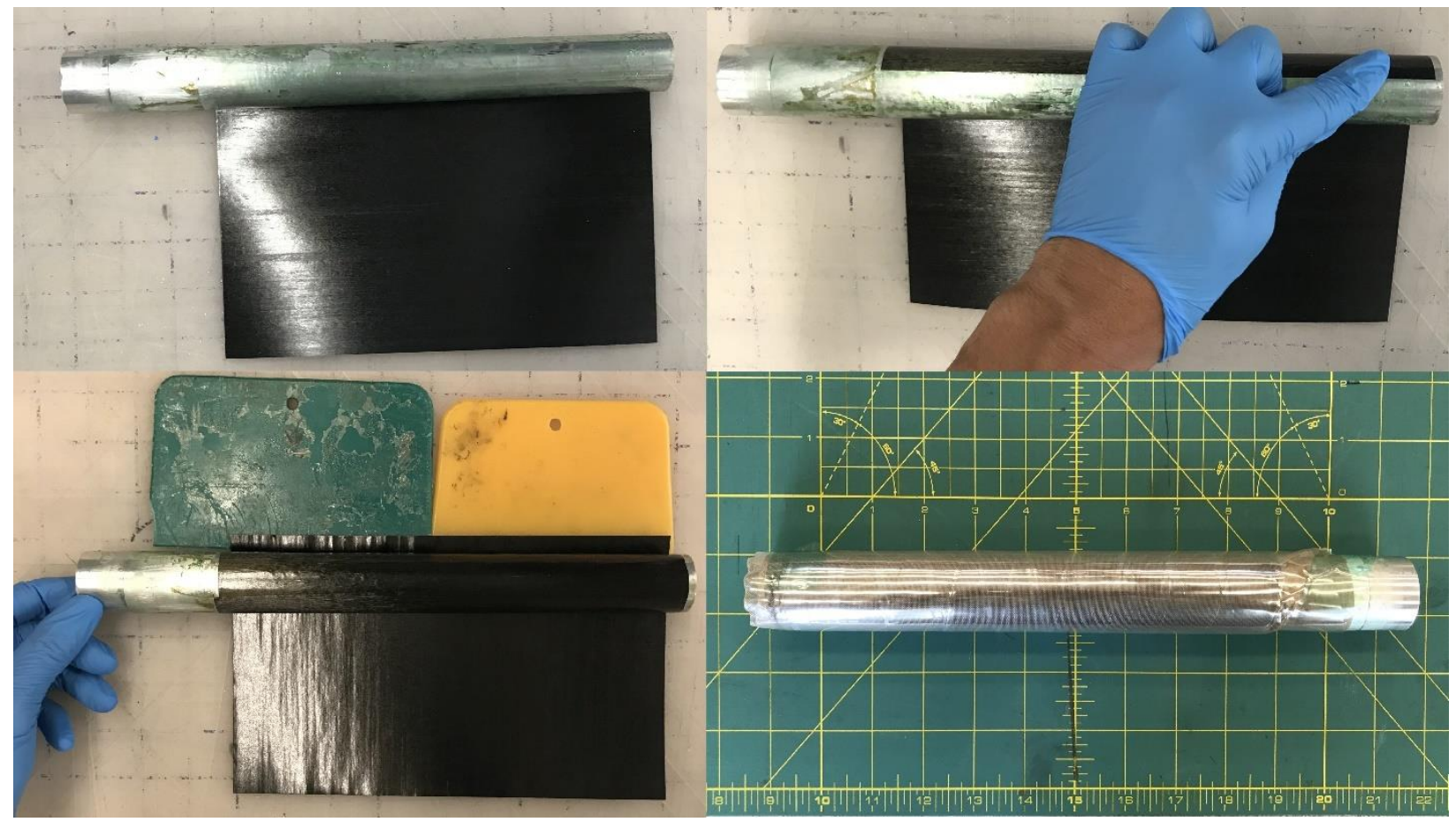

Figure 2.3 Composite Overwrapping Layup Technique.

There was no automation used throughout the layup process. Although each ply of prepreg was cut to the exact same dimensions and rolled onto the mandrel at the exact same locations of the mandrel, there are still sight deviations between each tube layup considering that it was an overwrapping process completed by hand. The differences between each layup are minor and assumed not to skew the performance of the final cured tube specimens to a catastrophic degree.

As pictured on the left of Figure 2.4, the ends of the mandrel were capped with small pieces of cotton breather to ensure the sharp aluminum edges on the ends of the mandrel would not rupture the vacuum bag when the air is purged. Also seen in Figure 2.4, is the overwrapped mandrel vacuum bagged in a cradle of cotton breather to mitigate wrinkling during cure due to excessive vacuum compaction force along a single axis of the tube. Finally, as seen in Figure 2.4, 
the completed vacuum bag was suspended in both the oven and autoclave during cure to mitigate the possibility of wrinkling due to the normal force of the tube resting on the ground of either curing vessel.

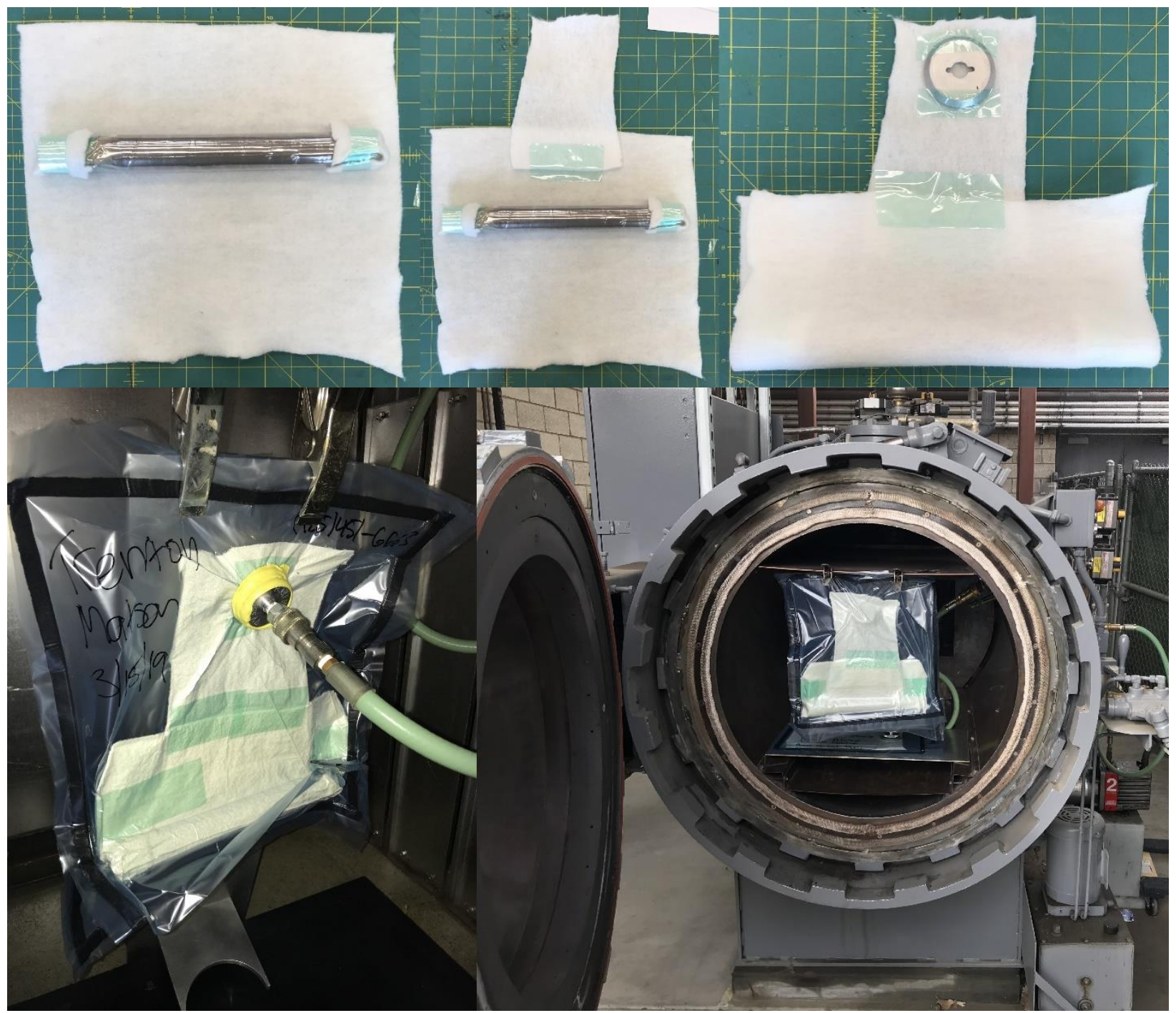

Figure 2.4 (Top) Tube Specimen Vacuum Bagging Method. (Bottom) Tube Specimen Hanging Cure Method in Both the Oven (Left) and the Autoclave (Right.)

As recommended by TenCate, the prepreg OoA cure cycle is pictured on the left of Figure 2.5. Considering the TC275-1 resin system is designed to cure in a conventional oven 
with vacuum pressure only, the autoclave cure cycle was designed solely for this research experiment. The autoclave cure cycle for the TC275-1 resin system, pictured on the right of Figure 2.5, was derived heavily from the cure cycle for the TenCate RS-36 resin system because of the similarity in neat resin properties between the two resin systems. The cure cycle plots below represent the temperatures and pressures that the oven and autoclave cycle through during the entirety of the prepreg cure cycles. The blue lines represent temperature while the red line represents pressure.
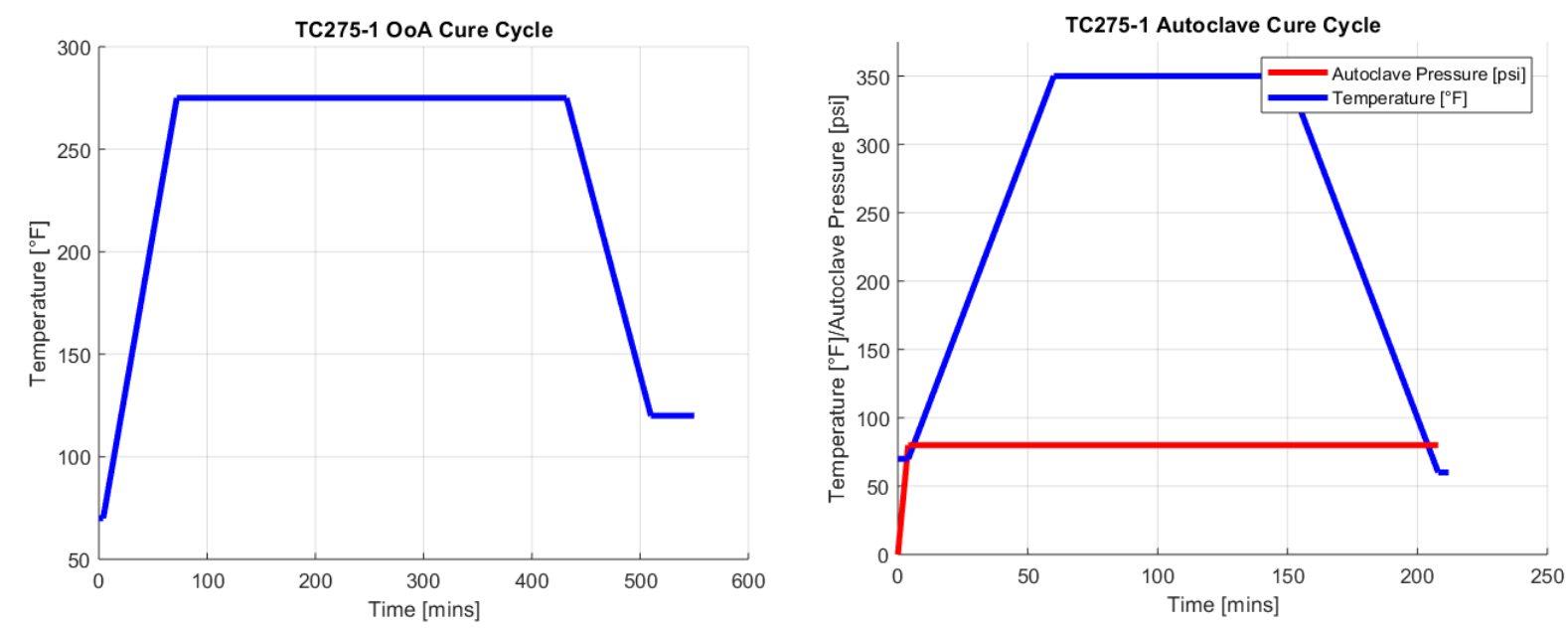

\section{Figure 2.5 Tube Specimen Oven Cure Cycle (Left.) Tube Specimen Autoclave Cure Cycle (Right.)}

After curing, the mandrels were removed from the curing vessel, removed from the vacuum bag, and had the peel-ply and compression tape unwrapped. The cured tube and mandrel were then frozen to decrease the diameter of the mandrel, and a rubber mallet was used to knock the mandrel out of the cured tube. The final cured tube is pictured on the left of Figure 2.6. The tube specimens, pictured on the right of Figure 2.6, were then cut to length using an 8" RIDGID R4040 tile saw with a 5/8" rotating diamond blade powered at 5000 RPM. The tube specimens 
were then carefully hand-sanded with 100-grit sandpaper to ensure even and parallel contact of the bottom and top edges of the tubes with the loading platens. The top edges were also chamfered at a $45^{\circ}$ angle with a Scotch Brite belt sander to inhibit a stable collapse failure mode at the top of the specimen. The chamfer also reduces the initial load peak, which mitigates cracking and fracturing before collapse [21]. Considering the chamfering process was also a byhand process that did not involve any automation, there are deviations of material removal between each tube. Also, note that for tubes 1,2, 7, and 8, the chamfering process compromised the parallel edges that ensured perfect contact on both the top and bottom edges during testing. Further material removal was deemed undesirable because of the risk of compromising the structural integrity of the specimens and to mitigate further deviations between the specimens and the nominal geometric ratios, such as D/t and L/D.

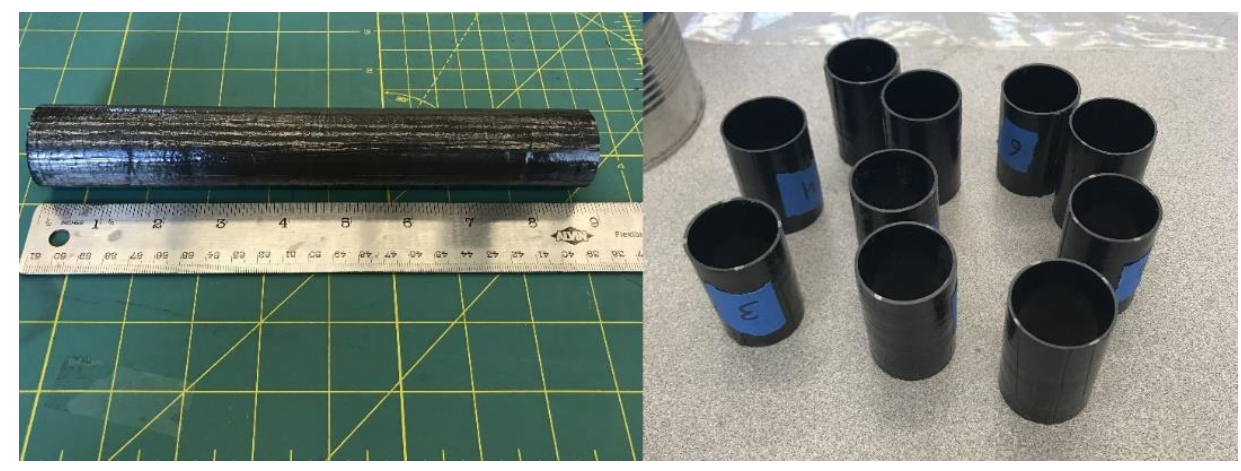

Figure 2.6 Final Cured Tube (Left.) Final Cured Tube Specimens (Right.)

Finally, as seen on the left of Figure 2.7 three-element BX120-2CA $120 \Omega$ Foil Resistance Rosette strain gages were bonded on the surface of the tube specimens to take measurements for strain and shear modulus calculations. For reference, the directional designations that are used in this paper are pictured on the right in Figure 2.7. The tube surfaces were prepared with 100-grit 
sandpaper and the strain gauges were bonded using Micro Measurements 200 Catalyst-C and MBond 200 adhesive. The geometric properties of all the tube specimens are included below in Table 2.1.
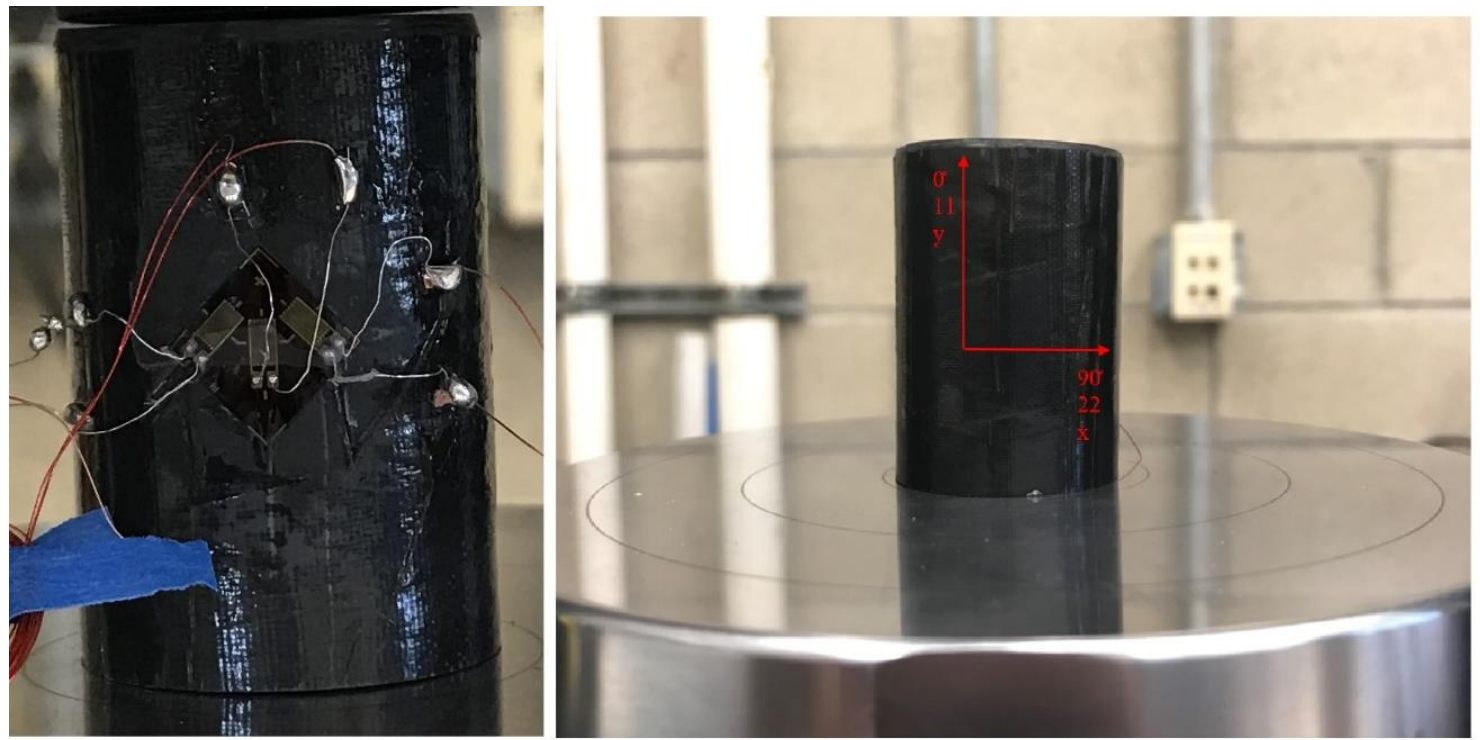

Figure 2.7 Strain Gauge Orientation (Left). Coordinate Systems Used to Designate Tube Specimen Directions (Right).

Table 2.1 Tube Specimens Final Dimensions.

\begin{tabular}{|c|c|c|c|c|c|c|c|}
\hline $\begin{array}{c}\text { Specimen } \\
\text { Number }\end{array}$ & Cure Type & $\begin{array}{c}\text { Length } \\
{[\mathbf{m m}]}\end{array}$ & $\begin{array}{c}\text { OD1 } \\
{[\mathbf{m m}]}\end{array}$ & $\begin{array}{c}\text { t_avg } \\
{[\mathbf{m m}]}\end{array}$ & $\begin{array}{c}\text { Mass } \\
{[\mathbf{g}]}\end{array}$ & $\mathbf{L} / \mathbf{D}$ & D/t \\
\hline 1 & OoA & 50.73 & 33.68 & 1.165 & 9.497 & 1.506 & 28.910 \\
\hline 2 & OoA & 47.03 & 33.07 & 1.208 & 8.260 & 1.422 & 27.387 \\
\hline 3 & OoA & 48.97 & 32.12 & 1.133 & 8.466 & 1.525 & 28.362 \\
\hline 4 & OoA & 47.14 & 33.42 & 1.230 & 8.255 & 1.411 & 27.171 \\
\hline 5 & OoA & 50.46 & 32.71 & 1.203 & 8.875 & 1.543 & 27.202 \\
\hline 6 & OoA & 48.15 & 32.40 & 1.203 & 8.560 & 1.486 & 26.944 \\
\hline 7 & Autoclave & 51.62 & 33.55 & 1.153 & 9.625 & 1.539 & 29.111 \\
\hline 8 & Autoclave & 49.76 & 32.63 & 1.228 & 9.244 & 1.525 & 26.582 \\
\hline 9 & Autoclave & 48.57 & 33.06 & 1.295 & 9.250 & 1.469 & 25.529 \\
\hline 10 & Autoclave & 51.21 & 33.40 & 1.318 & 9.745 & 1.533 & 25.351 \\
\hline
\end{tabular}




\subsection{Experimental Procedure}

The following section will expand on details pertaining to the experimental testing procedure for the tube specimens. These details include but are not limited to testing equipment, specimen loading rates, peak loading conditions, experimental boundary conditions, and data analysis techniques.

\subsubsection{Experimental Testing Equipment}

All mechanical testing was performed with an INSTRON 5969 tensile testing tower equipped with a $50 \mathrm{kN}$ load cell in conjunction with the BlueHill3 DAQ software. The two phases to the experimental testing included elastic deformation testing and bearing stress testing.

\subsubsection{Elastic Deformation Testing Procedure}

The purpose of the elastic deformation testing was to collect measurements from the adhered strain gauges during the linear elastic region to assist with numerical validation and to compare material properties of each tube. Sample defect tubes that were not equipped with strain gauges were preliminarily tested to assist with gathering loading parameters. The initial loading rate was chosen to be $2 \mathrm{~mm} / \mathrm{min}$ because it was a widely used loading rate for testing tube specimens in compression from the literature review; however, preliminary tests exhibited audible cracks and other microfractures that were deemed undesirable. The peak load was chosen to be $10 \mathrm{kN}$ because the tubes were consistently able to be loaded to this value while remaining in the linear elastic region. 
The tube specimens were exposed to quasi-static compression loads between two flat platens constantly displaced at $0.5 \mathrm{~mm} / \mathrm{min}$ to reflect a strain rate of $10^{-5}[1 / \mathrm{secs}]$. Each tube was placed on the stationary bottom platen while the resistance in each of the gauges was confirmed to read $120 \Omega$ with a multimeter. After the resistance confirmation measurements were conducted, the strain gauges were connected to INSTRON strain gauge adapter and calibrated to the BlueHill3 software. The specimens were loaded to a peak load value of $10 \mathrm{kN}$ before they were unloaded, and the next strain gauge connected. Pictured in Figure 2.8, a pad of thick cotton breather was placed on the top edge of the specimen to increase the likeliness of even loading contact. An example of experimental strain gauge readings from elastic deformation testing with and without the cotton breather pad are pictured in Appendix A. The tests that utilized the cotton breather pad breaded much more accurate and repeatable results as compared to the tests that the top loading platen was in direct contact with the top edges of the tube specimens. The INSTRON exported load-displacement curves generated from the installed load cell and extensometer, and the BlueHill3 software collected measurements from the adhered strain gauges. All subsequent data analysis was completed in MATLAB and Microsoft Excel. 


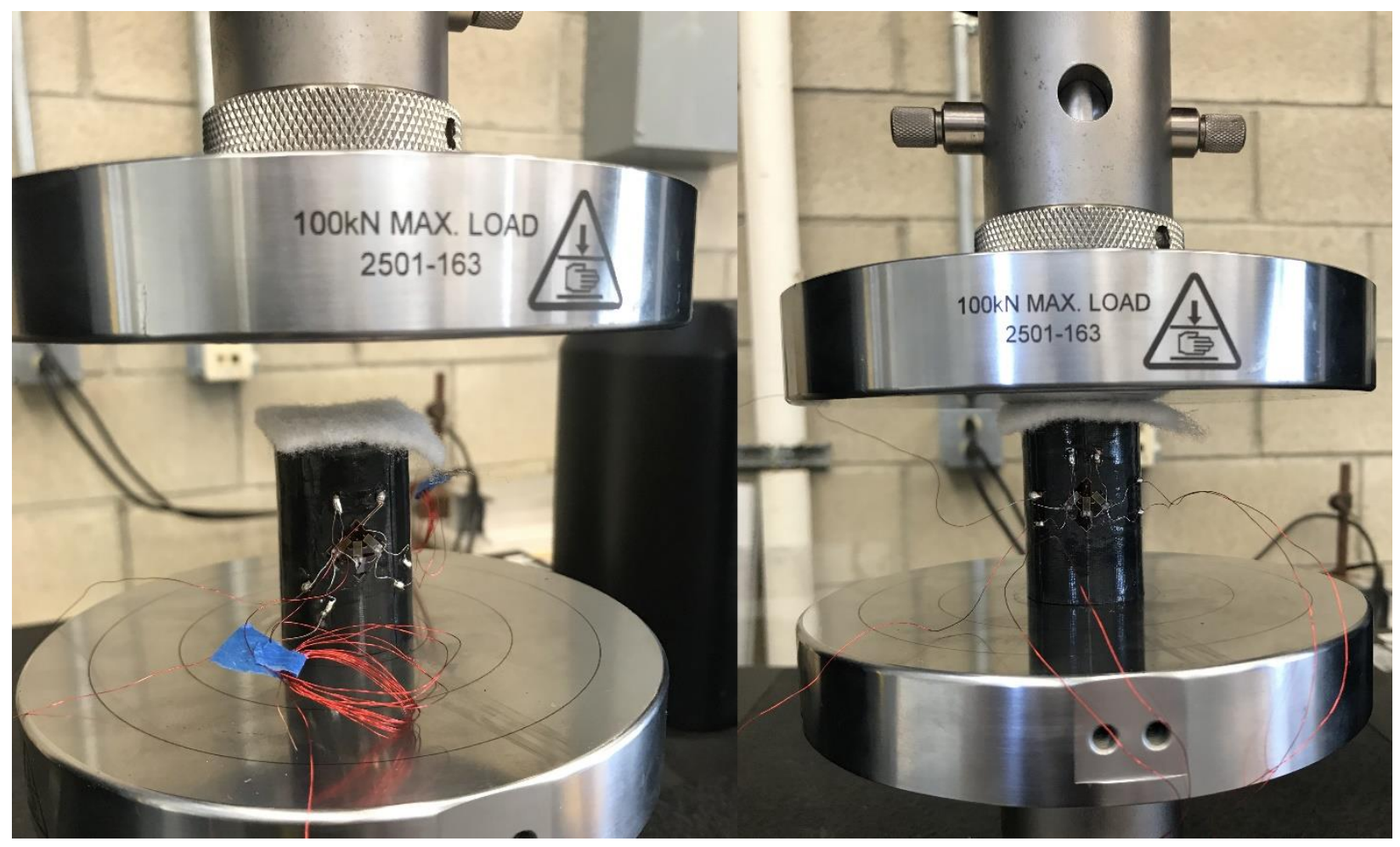

Figure 2.8 Elastic Deformation Experimental Testing Setup

\subsubsection{Bearing Stress Testing Procedure}

Contrary to compressive stress, bearing stress, also known as compressive normal stress, is an internal stress caused by compressive stress. Bearing stress is the contact pressure between two bodies, which in this case are the loading platen and the top edge of the tube specimen. The amount of force the compression load applies to the tube specimen depends on the mode of the contact. The purpose of the bearing stress testing was to monitor the deformation modes until densification and the crushing parameters of each tube. The tube specimens were exposed to quasi-static compression loads between two flat platens constantly displaced at $2 \mathrm{~mm} / \mathrm{min}$ until densification. Considering the deformation modes and crushing parameters were the focus of the bearing stress testing, the lead wires to the strain gauges were cut before the test began and no strain measurements were taken. Also, the cotton breather pad was not utilized because the strain 
measurements in the linear elastic region of deformation are observed as negligible compared to the overall plastic deformation of the specimens. 


\section{THEORETICAL EXACT SOLUTION}

A theoretical exact solution is found during the completion of this study. This solution is computed using stiffness matrices calculated using the Classical Lamination Theory for composite laminates, which uses material properties from each lamina that is used to layup a certain stacking sequence to calculate the material properties of the final layup. In this study, the factory specified material properties from TenCate are used to calculate the theoretical solution. This solution will be compared with the Modulus values that are gathered experimentally to help assess the validity of the experimental results.

\subsection{Classical Lamination Theory}

A laminate is an organized stack of UD composite plies. The stack is defined by a stacking sequence, which indicates the directions of each ply. The stacking sequence is chosen for a certain application because the fiber directions in each ply can be manipulated to give the laminate different properties. For example, a symmetric cross-ply laminate will have very similar strengths and stiffnesses in each direction (11 and 22 directions) because there are the same number of plies in each direction. The mechanical properties of each ply will be known and released by the manufacturer in respective spec sheets; however, it is essential to be able to calculate the mechanical properties of the entire laminate. The Classical Lamination Theory (CLT) is a widely utilized method to calculate the mechanical properties of laminates from the geometric and mechanical properties of each ply. CLT uses calculated matrices, such as the reduced stiffness matrix $(\mathrm{Q})$, and matrix multiplication of defined mechanical and environmental loads to predict stresses and strains that the laminate will experience during loading. 


\subsection{Theoretical Modulus Calculations}

MATLAB was used to setup a CLT code that calculated the reduced stiffness, laminate stiffness, and laminate compliance matrices. These matrices were then manipulated to find the extensional compliance matrix that is used to calculate theoretical Modulus values. Using equation 3.1 below, the theoretical value for $\mathrm{E}_{11}$ was calculated to be $144 \mathrm{GPa}$ using the specified Modulus values from the manufacturer and CLT for composite laminates, where $\mathrm{h}$ is the laminae thickness and $\mathrm{A}^{*}$ is the extensional compliance matrix, which is derived in Appendix B.

$$
E_{11}=\frac{1}{h A_{11}^{*}}
$$

The theoretical calculated CLT value for $\mathrm{E}_{22}$ is calculated to be $93 \mathrm{GPa}$ using equation 3.2 where $\mathrm{h}$ is the laminae thickness and $\mathrm{A}_{22}{ }_{22}$ is the $5^{\text {th }}$ element in the extensional compliance matrix.

$$
E_{22}=\frac{1}{h A_{22}^{*}}
$$




\section{NUMERICAL SOLUTION}

Along with a theoretical exact solution, a numerical solution is calculated for this study using the ABAQUS finite-element analysis (FEA) program. The experimental task is modeled in ABAQUS, and strain values that were measured during experimental testing will be compared with strain calculations from the FEA model. Similar to the theoretical solution, the numerical solution will be compared with the experimental results to help assess the validity of the results.

\subsection{Numerical Model Setup}

ABAQUS CAE is used to attain the numerical solution for deformation in the tube specimens and to compare strain values measured during the experimental testing. The numerical model employs a plane stress assumption, which ignores the stress in the direction that is normal to the tube surface (Z-direction). The stresses in the Z-direction are negligible because of the thin-walled assumption, which is valid in this case because the wall thickness is less than $1 / 10$ of the length of the tube. To model the tube, a CAD model of a solid cylinder is created in accordance with the average OD and height of the tube specimens. After the file is imported into ABAQUS, the software "shells" the model, which essentially creates an infinitely thin outer surface to the tube.

As pictured in Figure 4.1, the model was meshed with quadrilateral elements and solved explicitly with reduced integration. Rather than quadratic interpolation, the linear interpolation of 3 nodes per element edge was used in the solution considering the specimen is not experiencing large bending deformations during loading [22]. A Displacement/Rotation boundary condition (BC) was applied to the bottom tube edge that restricts the displacement in the y-direction of the tube and the rotation in the y-direction of the tube. This BC essentially allows the tube to expand 
in the $\mathrm{x}$ and $\mathrm{z}$-directions while it is compressed in the $\mathrm{y}$-direction. It also restricts the tube from torqueing during loading but allows it to buckle. One node was chosen to be fixed in both the $\mathrm{x}$ and z-directions on the bottom edge of the tube to prevent divergent deformation results. Restricting this node essentially gives the tube a fixed reference point that will allow the remainder of the nodes to deform appropriately in relation to it without shooting the solution into infinity.
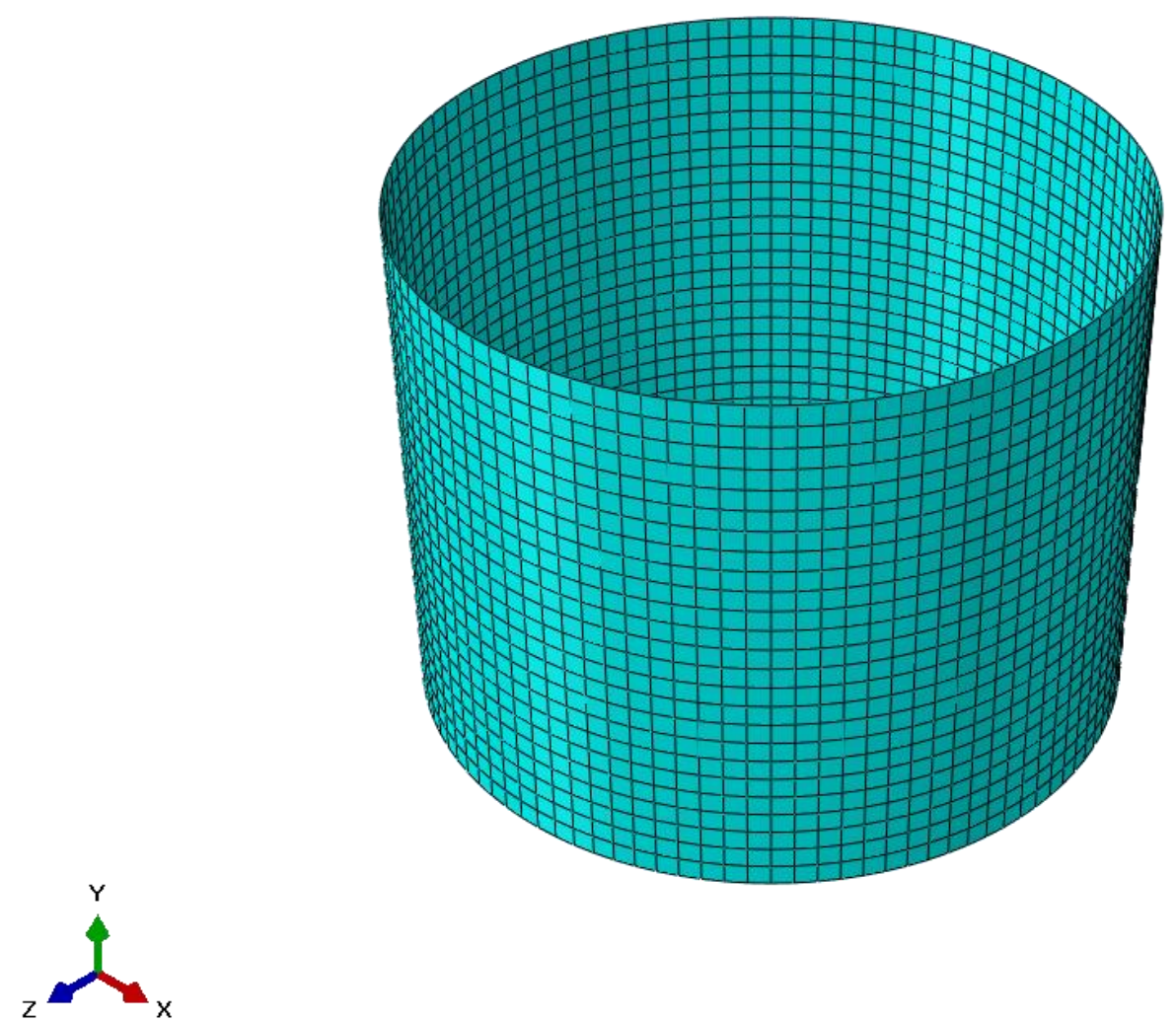

Figure 4.1 Meshed Tube Model for the Numerical Solution. 
The constant loading stress value was chosen to reflect a certain instant during experimental testing that was consistently in the middle of the linear elastic region of the loadextension plots. The average cross-sectional area of all the tubes was used with the load value of $5 \mathrm{kN}$ to calculate a stress value of $41 \mathrm{MPa}$, which was input as the load on the top edge of the tube. The area on the surface of the tube that was covered by the strain gauges was partitioned in the ABAQUS model, and the strain values were averaged amongst all the nodes that were within the partitioned area. The corresponding experimental strain gauge measurements at $5 \mathrm{kN}$ were then compared to the averages of the strains from the partitioned area. 


\section{RESULTS AND ANALYSIS}

First, the stress-strain curves from the elastic deformation testing stage are analyzed and the calculated Modulus values are displayed. The transformed stress-strain curves are also displayed with the respective Modulus values displayed as well. Next, the crushing parameters that were gathered and calculated from the bearing stress testing are analyzed and compared between test conditions, OoA and autoclaved specimens. Each crushing parameter has an average value calculated for each condition and a percent difference comparison to the other condition. The theoretical and numerical solutions are then compared with averaged values from experimental testing. The average value comparisons include averaged values from each test condition and average value comparisons from the entire sample set. Finally, sources of error throughout the completion of this Thesis are presented at the end of this section.

\subsection{Elastic Deformation Testing}

Strain measurements from the linear elastic compression tests were used to calculate $\mathrm{E}_{11}$ of the tube specimens. A theoretical bearing stress calculation was preformed using equation 5.1 below, where $\sigma$ is the stress, $\mathrm{P}$ is the load, and $\mathrm{A}$ is the cross-sectional area of the specimen with respect to the loading direction. As seen in Figure 5.1, the linear elastic stress-strain curve was plotted and $\mathrm{E}_{11}$ was calculated by finding the slope of the stress-strain curve using the slope() command in Microsoft Excel. The calculated Modulus values are all included below in Table 5.1 and represented graphically in Figure 5.2. The results from Tube 4 elastic testing were ignored because cracking and broken fibers were observed during the test.

$$
\sigma=\frac{P}{A}
$$


Table 5.1 Final Measured E11 Values for All Tube Specimens from Elastic Deformation Testing.

\begin{tabular}{|c|c|c|}
\hline Tube Number & Measured Modulus E11 [GPa] & Cure Type \\
\hline 1 & 81.700 & OoA \\
\hline 2 & 76.903 & OoA \\
\hline 3 & 82.45 & OoA \\
\hline 4 & N/A & OoA \\
\hline 5 & 64.179 & OoA \\
\hline 6 & 90.442 & OoA \\
\hline 7 & 85.639 & Autoclave \\
\hline 8 & 76.276 & Autoclave \\
\hline 9 & 119.571 & Autoclave \\
\hline 10 & 124.907 & Autoclave \\
\hline
\end{tabular}

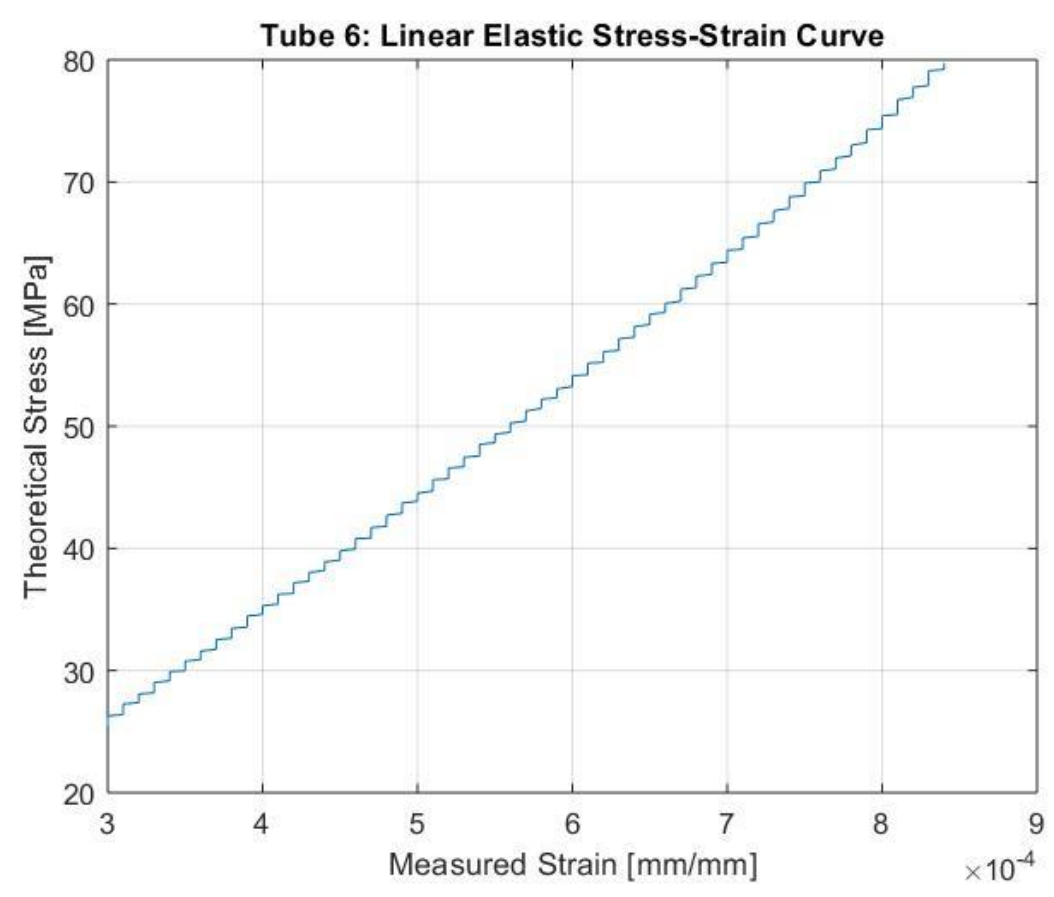

Figure 5.1 Linear Elastic Stress-Strain Curve Measured During Elastic Deformation Testing. 

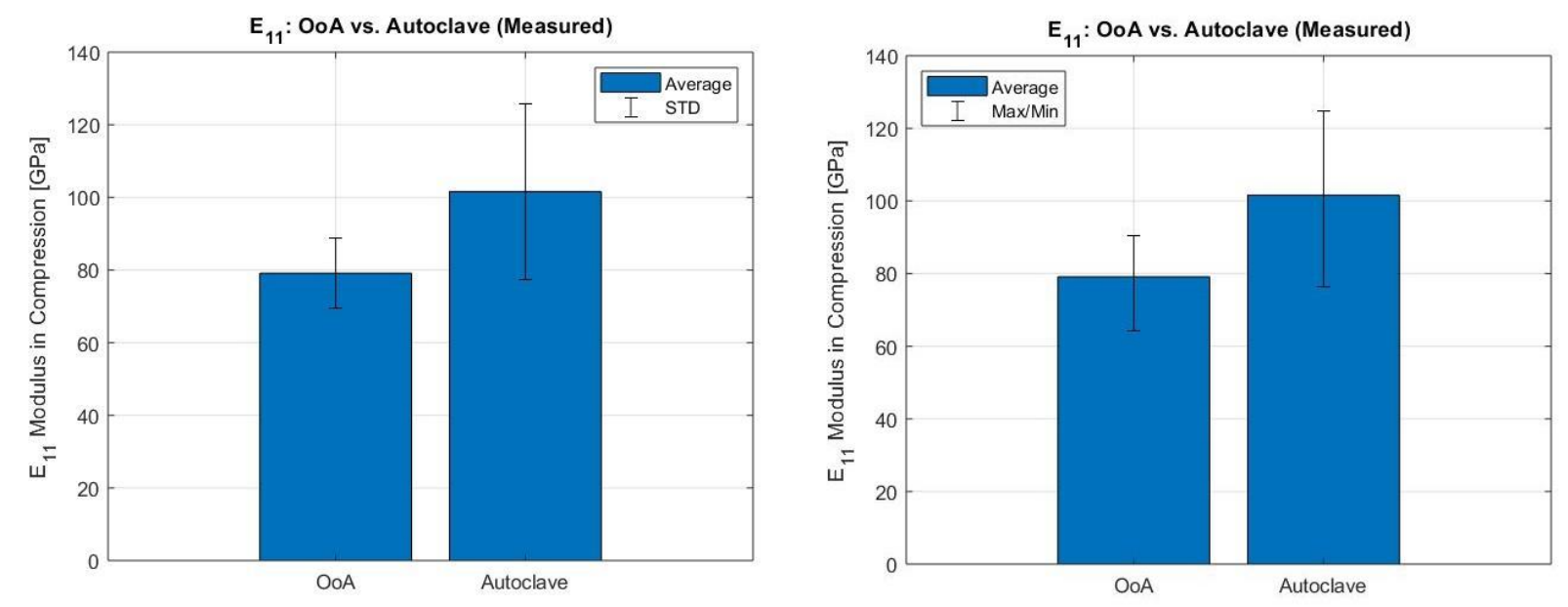

\section{Figure 5.2 Bar Graph Representation of the Comparison of Measured E11 Values Gathered from Elastic Deformation Testing.}

As seen in Figure 5.2, the autoclaved specimens are on average 22.1\% stiffer than the OoA specimens in the $0^{\circ}$ direction under compressive forces. Despite the percent differences between the two specimen types are smaller and Kellas et al. loaded their specimens in tension rather than compression, this relationship agrees with the experimental results gathered by Kellas et al. [1]. Pictured on the left of Figure 5.2 is the average measured $E_{11}$ value for each test condition plotted with error bars signifying the standard deviation of the sample sets, and pictured on the right of Figure 5.2 are the average values plotted with error bars signifying the maximum and minimum measured values in each case. Although the differences between the maximum and minimum values seen amongst the tested tubes is non-trivial, the discrepancies between the two values in both cases are very similar. Also, the large difference in modulus values seen in Tubes 7 and 8 as compared to the other autoclaved specimens can most likely be attributed to the phenomenon of mixed deformation modes. A combination of shearing deformation before the loading platens have uniform contact with all tube edges and axial deformation experienced after uniform contact can detrimentally alter strain measurements. In 
addition, Tube 7 was observed to have the most noticeable wrinkle out of all the specimens, which can also seriously affect the measured strain values due to geometrical defects.

$\mathrm{E}_{22}$ also needed to be calculated to complete the necessary data for the numerical and theoretical solutions. The elastic testing data analysis encompassed transforming the strain measurements in the $-45^{\circ}, 0^{\circ}$, and $+45^{\circ}$ directions to the $\mathrm{y}, \mathrm{x}$, and $\mathrm{xy}$ directions. The plane strain transformation equations below were used to calculate the strain experienced in the $90^{\circ}$ direction of the tube specimens [23].

$$
\begin{gathered}
\varepsilon^{\prime}{ }_{x}=\frac{\varepsilon_{x}+\varepsilon_{y}}{2}+\frac{\varepsilon_{x}-\varepsilon_{y}}{2} \cos 2 \theta+\frac{\gamma_{x y}}{2} \sin 2 \theta \\
\varepsilon^{\prime}{ }_{y}=\frac{\varepsilon_{x}+\varepsilon_{y}}{2}-\frac{\varepsilon_{x}-\varepsilon_{y}}{2} \cos 2 \theta-\frac{\gamma_{x y}}{2} \sin 2 \theta \\
\frac{\gamma_{x y}^{\prime}}{2}=-\frac{\varepsilon_{x}-\varepsilon_{y}}{2} \sin 2 \theta+\frac{\gamma_{x y}}{2} \cos 2 \theta
\end{gathered}
$$

After the transformed strains were calculated, the respective stresses were calculated through matrix multiplication of the reduced stiffness matrix and the strain vector. As seen in the equations below, the reduced stiffness matrix for a composite laminate is calculated using CLT with the nominal manufactured values released by TenCate for the UD tape that was used to manufacture the tube specimens.

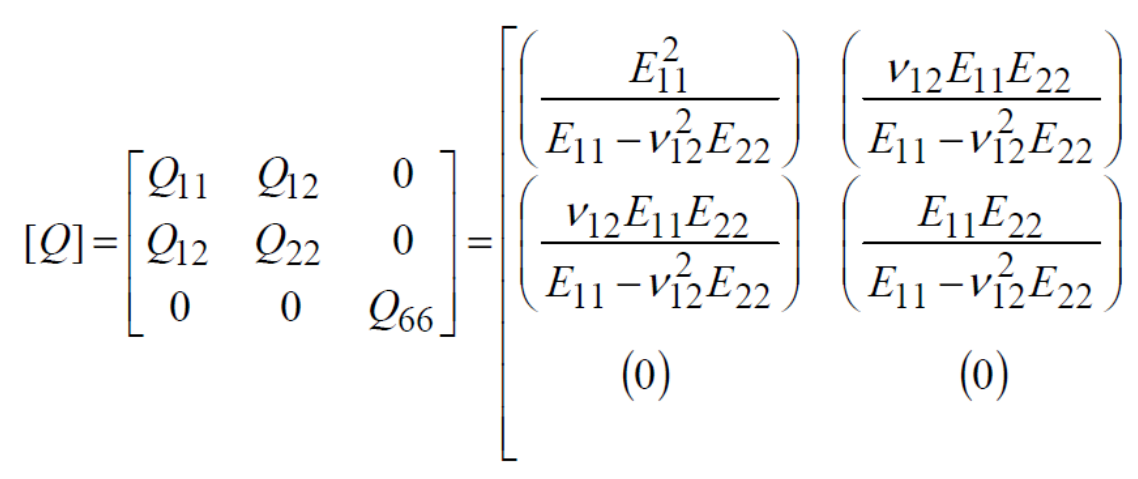




$$
\left\{\begin{array}{c}
\sigma_{1} \\
\sigma_{2} \\
\tau_{12}
\end{array}\right\}=\left[\begin{array}{ccc}
Q_{11} & Q_{12} & 0 \\
Q_{12} & Q_{22} & 0 \\
0 & 0 & Q_{66}
\end{array}\right]\left\{\begin{array}{c}
\varepsilon_{1} \\
\varepsilon_{2} \\
\gamma_{12}
\end{array}\right\}
$$

As seen in Figure 5.3, the transformed stress-strain curves in the x-direction of the tube specimens were plotted, and $\mathrm{E}_{22}$ was calculated by finding the slopes of the linear portions of the respective curves. All the calculated values for $\mathrm{E}_{22}$ can be found listed in Table 5.2 below.

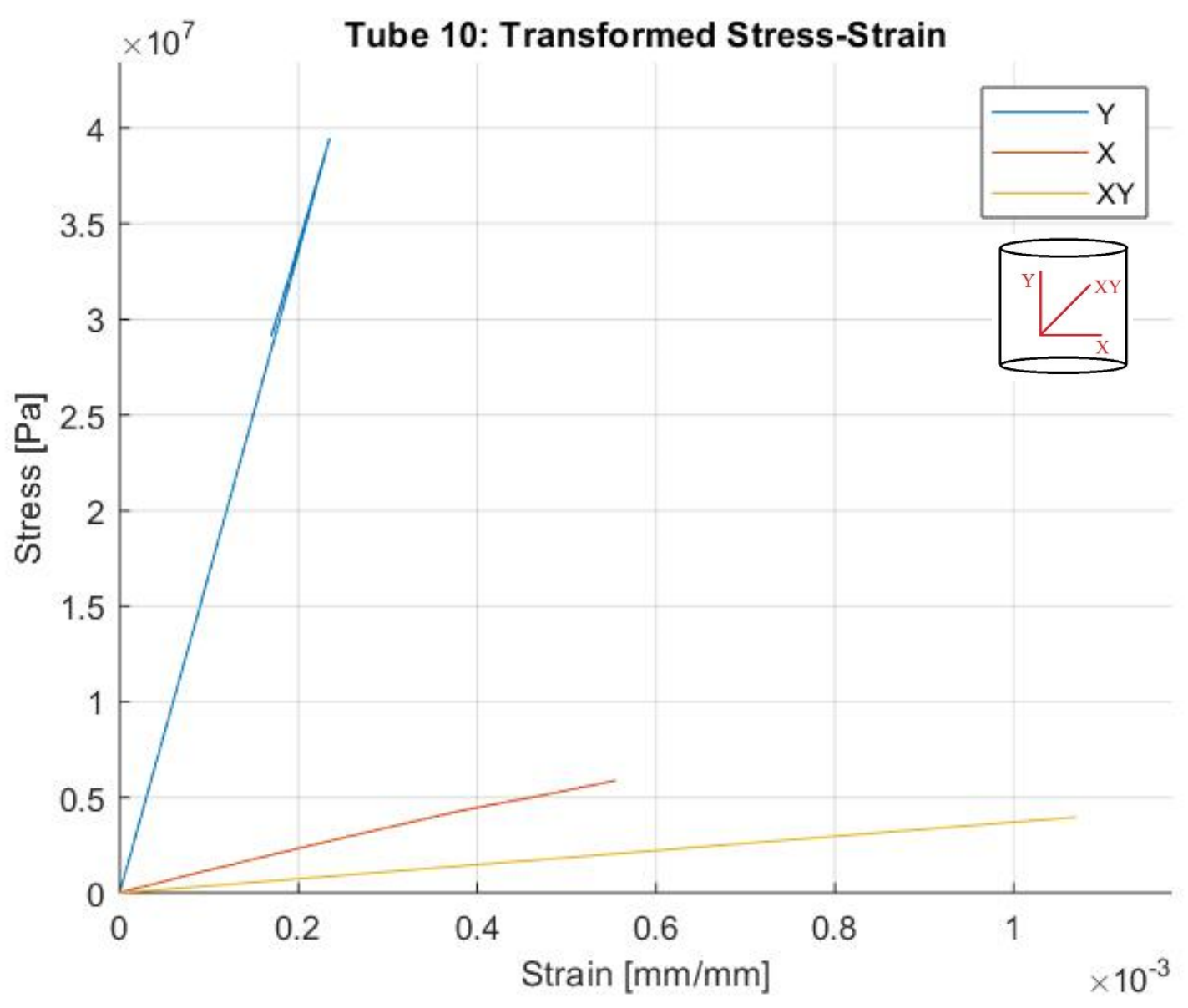

Figure 5.3 An Example of the Transformed Strain Components Calculated from Data Gathered During Elastic Deformation Testing. 
Table 5.2 Final Measured E22 Values for All Tube Specimens from Elastic Deformation Testing.

\begin{tabular}{|c|c|c|}
\hline Tube Number & Measured Modulus E22 [GPa] & Cure Type \\
\hline 1 & 67.665 & OoA \\
\hline 2 & 70.143 & OoA \\
\hline 3 & 110.052 & OoA \\
\hline 4 & N/A & OoA \\
\hline 5 & 58.552 & OoA \\
\hline 6 & 118.696 & OoA \\
\hline 7 & 62.417 & Auto \\
\hline 8 & 110.464 & Auto \\
\hline 9 & 127.952 & Auto \\
\hline 10 & 125.018 & Auto \\
\hline
\end{tabular}

\subsection{Bearing Stress Testing}

Time lapse videos were taken of each specimen to observe the deformation modes during each test. As seen below in Figure 5.4, all the specimens experienced the same failure mode, which was progressive end crushing from the top edge of the tube. Progressive crushing, or pulverization, is a commonly observed failure mode for composite tubes in compression. The high energy absorption associated with the large number of microfractures that occur as the tube crushes promotes yielding by plastic deformation. The energy dissipation results from the generation of fracture surface area, from friction between fragments, and from plastic shear of the matrix [9]. The crushing was initiated by the reduced cross-sectional area on the top edge of the tube due to the chamfering process. 


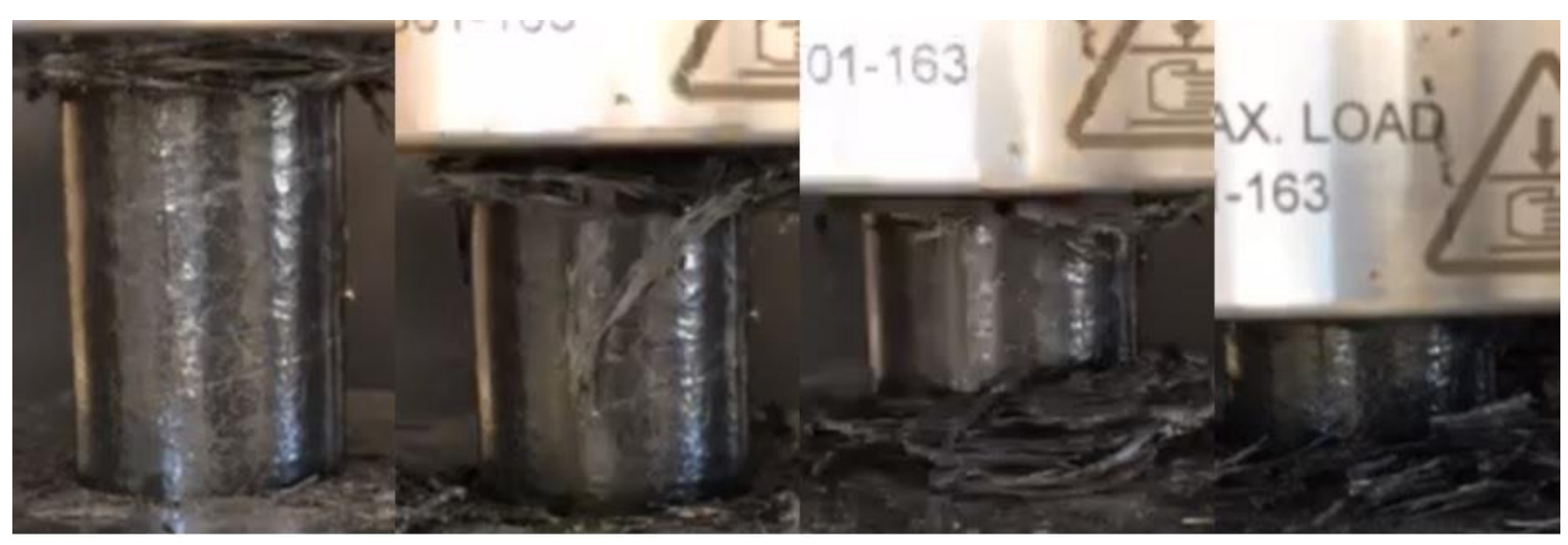

\section{Figure 5.4 Deformation Mode of the Tube Specimens Recorded from a Time-Lapse Video During Bearing Stress Testing.}

Each bearing stress test was split into three different regions: linear elastic, progressive crushing, and densification. These three regions are annotated on the load-extension plot for tube 4 below in Figure 5.5. The linear elastic region is characterized with a linear load-extension relationship and elastic deformation in the material. The elastic region ends at a maximum load value where progressive crushing will begin. The progressive crushing region includes splaying of the tube edges and a series of microfractures inside the tube as it is crushed until densification. As seen in the middle of Figure 5.5, the crushing region is characterized by oscillations about a median load value on the load-extension curve. As pictured in Figure 5.5, the beginning of densification is easily distinguishable by a positive increase in the load-extension relationship. The next section will outline the crushing parameters that will be used to measure the performance of the specimens during each of these regions. 


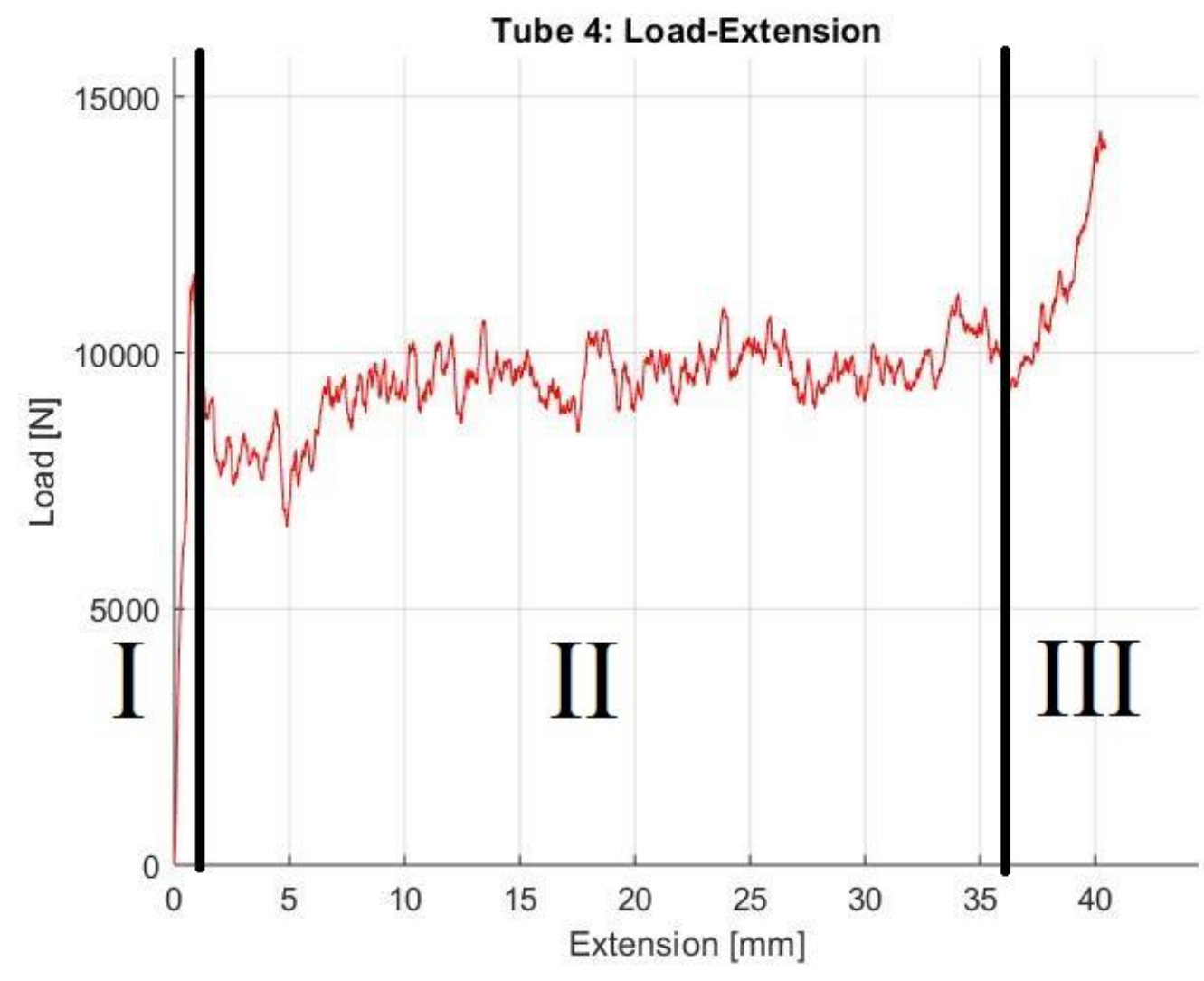

Figure 5.5 A Annotated Load-Extension Plot to Show the Different Regions Observed During Bearing Stress Testing.

\subsection{Crushing Parameters}

The crushing parameters that are used to characterize the crushing performance of the tube specimens are gathered from the bearing stress experimental testing.

\subsubsection{Energy Absorbed}

The first parameter, EA, is calculated by a numerical integration of the load-extension curve from the beginning of the test until the beginning of densification. However, EA is somewhat of an inaccurate metric for mechanical performance because a larger specimen with more mass will inherently be able to absorb more energy while it is deforming. 


$$
E A=\int_{0}^{\delta} F(\delta) d \delta
$$

As noted in Equation 5.9, the EA is attained in MATLAB by trapezoidal numerical integration of the load-extension curve from the beginning of the test until the beginning of densification. On average, the autoclaved specimens absorbed 3.3\% more energy during compression as compared to the OoA specimens; however, as pictured on the right of Figure 5.6, some OoA specimens absorbed more energy than their autoclaved counterparts. The higher average EA for the autoclaved specimen can be a function of decreased imperfections in the final part, but in this case, it is most likely related to the higher average mass for the autoclaved specimens. To accurately compare the two specimen types, the EA needs to be normalized by mass.
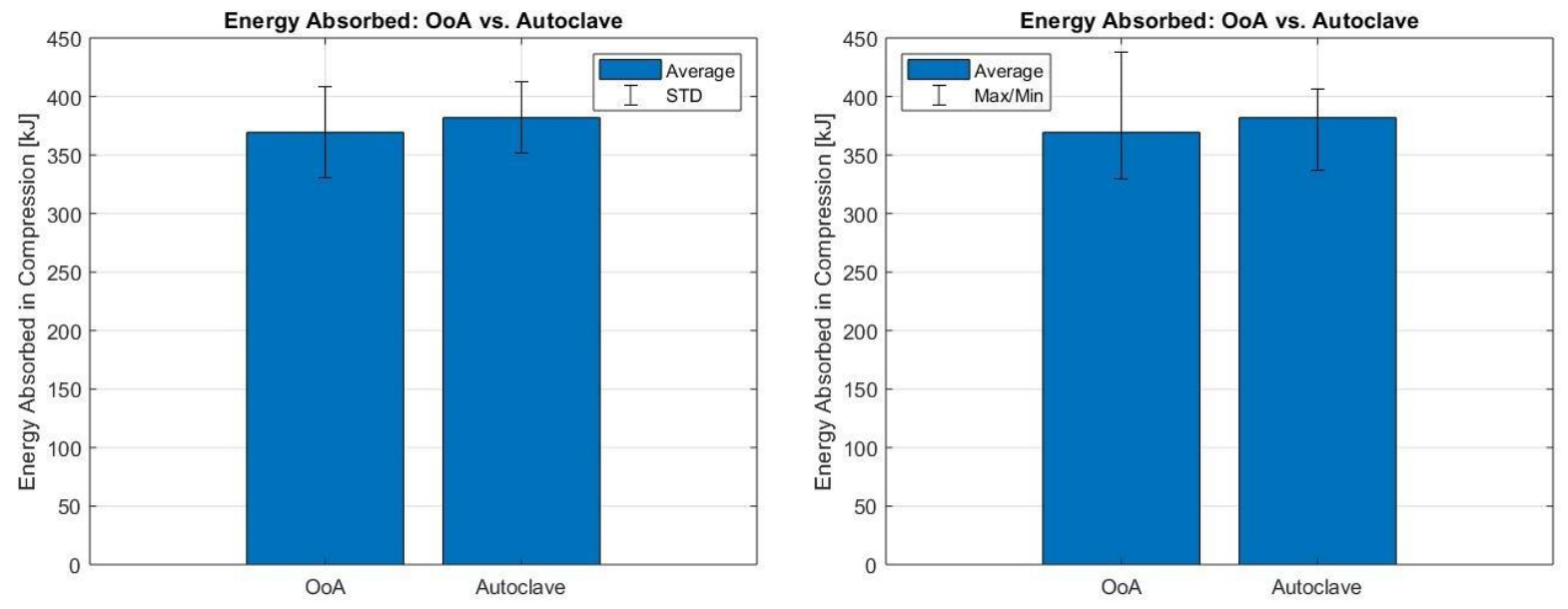

\section{Figure 5.6 Bar Graph Representation of the Comparison of Calculated EA Values Gathered from Bearing Stress Testing.}




\subsubsection{Specific Energy Absorption}

The next parameter, SEA, is calculated by normalizing the EA by the mass of each tube specimen.

$$
S E A=\frac{E A}{m}
$$

Typically, the crashworthiness increases with an increase in EA; however, SEA is a better metric for crashworthiness because it considers the mass of the object. Contrary to the results from the calculated EA, the OoA specimens on average absorbed 5.7\% more energy per unit mass than the autoclaved specimens. This finding supports the idea that the OoA specimens are better energy absorbers than the autoclaved specimens, especially because the autoclaved specimen that absorbed the most energy per unit mass is still less than the average of the OoA specimens.
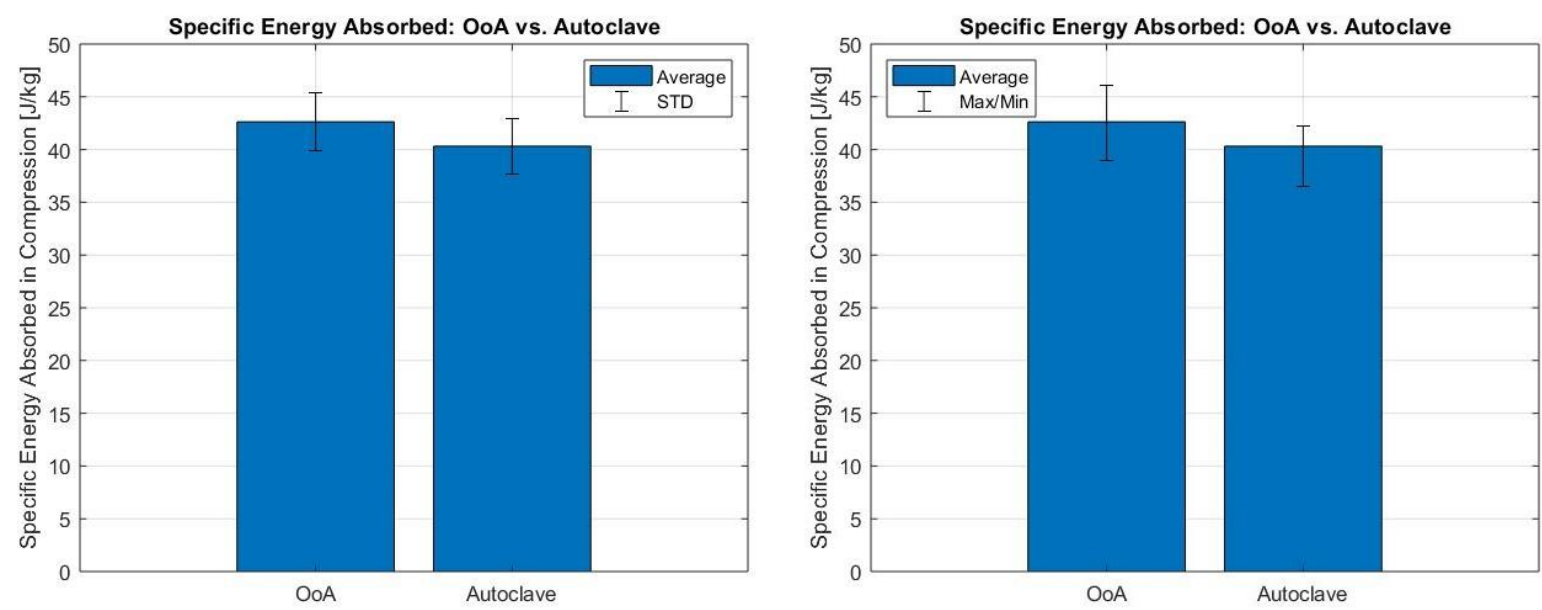

Figure 5.7 Bar Graph Representation of the Comparison of Calculated SEA Values Gathered from Bearing Stress Testing. 


\subsubsection{Maximum Load}

The maximum load, $\mathrm{P}_{\max }$, is taken to be the highest load value seen during testing before the progressive crushing region begins. In theory, more efficient crashworthy structures will be able to reach higher loads; however, high load capacities, especially with composite structures, can lead to more uncontrollable deformation in the specimen.

$$
P_{\max }
$$

The maximum load parameter is measured as the highest load reached before the specimen enters the progressive crushing region. As seen in Figure 5.8, the autoclaved specimens experienced on average $11.6 \%$ higher loads before entering the crushing region than the OoA specimens. The higher resistance to loading before progressive crushing begins is most likely attributed to the on average higher modulus values of the autoclaved specimens. Other factors that may affect the maximum load are decreased interlaminar voids in the autoclaved specimens and the on average higher mass and longer length of the autoclaved specimens. Although loadcarrying is a critical factor used to assess crashworthiness and energy absorption capabilities, high load capacities can lead to more catastrophic failure mechanisms [14]. A better measure to assess the crushing performance of the specimens utilizes the average load during the progressive crushing region as well. 

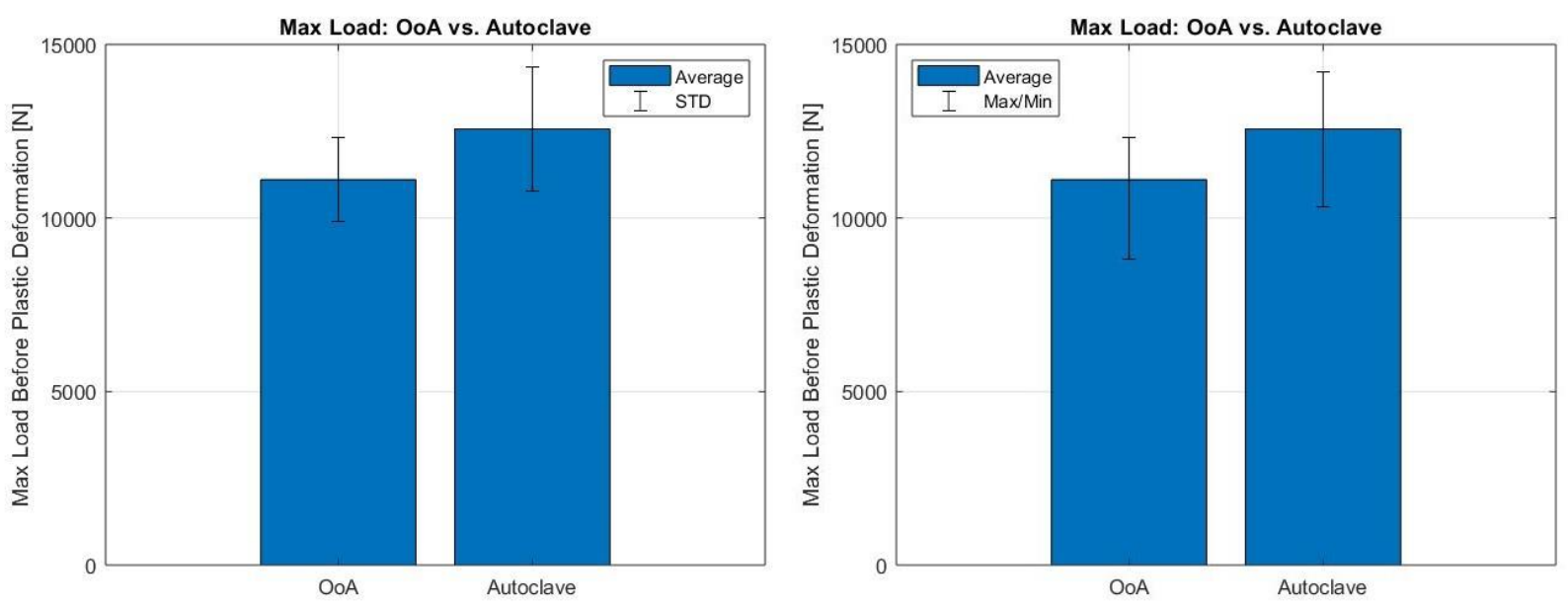

Figure 5.8 Bar Graph Representation of the Comparison of Measured Maximum Loads
Observed During Bearing Stress Testing.

\subsubsection{Average Load}

The average load, $\mathrm{P}_{\mathrm{avg}}$, is calculated to be the average load seen during the progressive crushing region.

$$
P_{\text {avg }}
$$

In this study, the average load is calculated by taking the mathematical mean of the loads experienced by the tube during the progressive crushing region. As seen in Figure 5.9, the autoclaved specimens experienced on average 5.4\% higher loads during the crushing region than the OoA specimens. Considering the autoclaved specimens averaged a higher maximum load, it is expected that they will also experience higher average loads. The mass and geometric properties of the autoclaved specimens can skew both the maximum and average load parameters so a better metric to characterize energy absorption involves normalizing the average load by the maximum loads. 

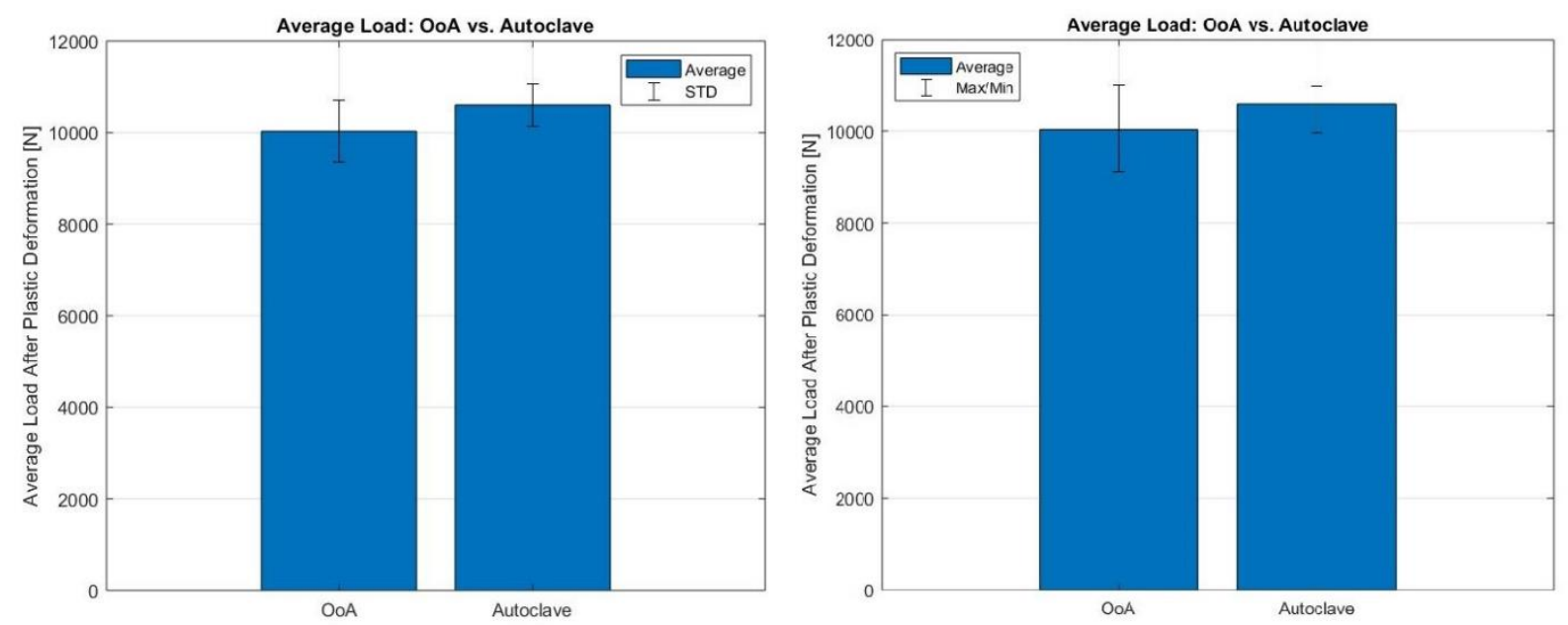

\section{Figure 5.9 Bar Graph Representation of the Comparison of Measured Average Loads Observed During Bearing Stress Testing.}

\subsubsection{Crush Force Efficiency}

The last parameter, CFE, is simply the ratio between the average and maximum loads.

$$
C F E=\frac{P_{\text {avg }}}{P_{\max }}
$$

CFE is a useful measure of the uniformity of the collapse load, which can help to quantify energy absorption performance. For an ideal energy absorber, $\mathrm{CFE}=1$, which essentially means the absorber collapses plastically at a constant force that is equal to its maximum load experienced before progressive crushing begins. In this ideal case, the absorber is also as compact as possible; however, in reality this is rarely the case and the crashworthiness is maximized by using an energy absorber with a high CFE [9]. Having an energy absorber perform with a CFE close to 1 is also important because this indicates that the structure is absorbing the $\mathrm{KE}$ of the impact or crash in a controlled manner. The primary objective for the design of a crashworthy structure is to absorb KE, through dissipative mechanisms such as material failure, in a controlled and predictable manner [10]. As seen in Figure 5.10, the CFE for the OoA 
specimens is on average $6.4 \%$ higher than the autoclaved specimens. Considering both averages are below 1, the increased CFE for the OoA specimens indicate increased crushing performance with respect to the classic definition of an effective energy absorber.
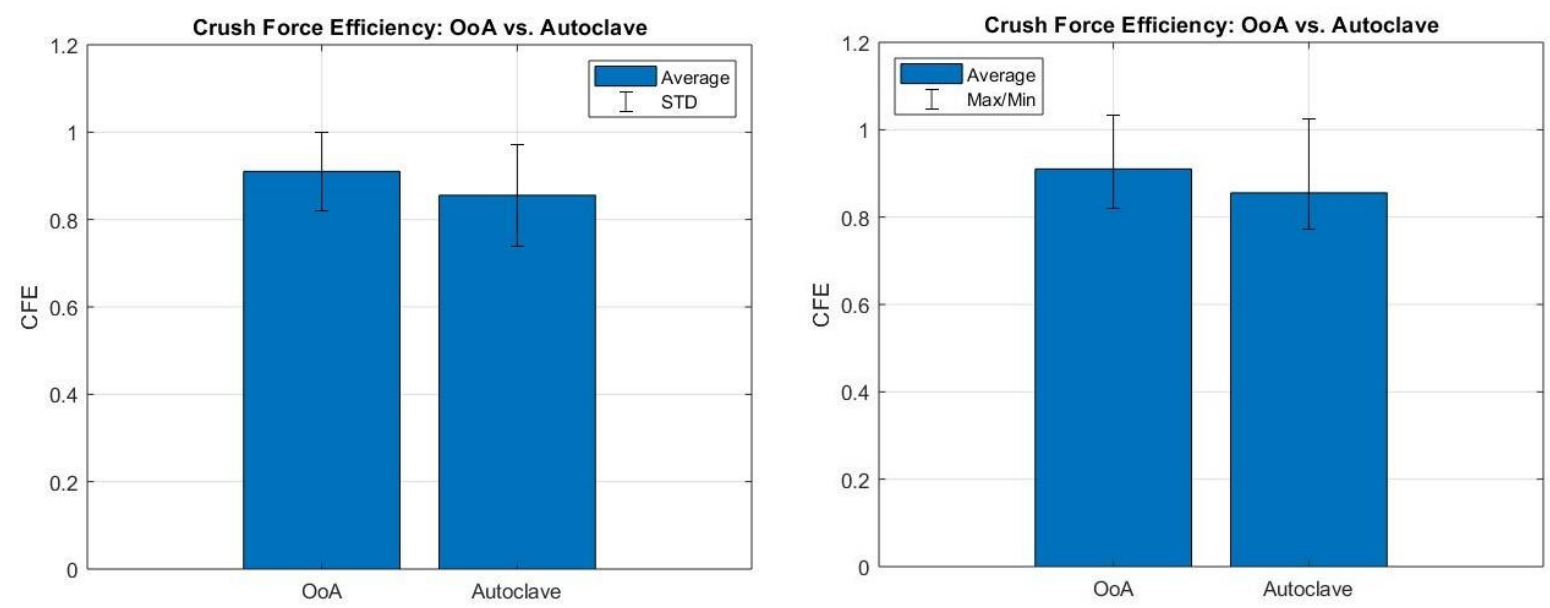

Figure 5.10 Bar Graph Representation of the Comparison of Calculated CFE Values Gathered from Bearing Stress Testing.

\subsection{Theoretical Comparison}

The 38\% discrepancy between the theoretical value and the average measured Modulus values is most likely due to the quality of the chosen material, which is a function of how the material was stored prior to the beginning of this project. Another factor that can detract from the stiffness of the part is the manufacturing process. Resin loss can occur from improper manufacturing methods, which will greatly decrease the strength of the final part [24]. In the case of this project, the recommended debulking procedure every 4 plies during the layup process was unable to be adhered to because wrinkling would occur unless the heat shrink tape was wrapped around the layup. This is evident because when the theoretical $\mathrm{E}_{11}$ value is compared with the average OoA Modulus values, the percent difference is much larger at $45 \%$. 
When compared with the autoclaved average values, the percent difference decreases to $29 \%$. These discrepancies agree with findings from Sutter et al. that OoA prepregs are more susceptible to final cured part mechanical deficiencies as compared to autoclave prepregs due to process-driven procedures, like debulking, and OL accumulation [6]. When the extreme outliers from the autoclaved measured modulus values are ignored, the discrepancy between the measured and theoretical values decreases to $15 \%$.

The theoretical $\mathrm{E}_{22}$ value differs from the average measured value of $94.5 \mathrm{GPa}$ by $1.6 \%$. Although the standard deviation (STD) of the entire sample set is $29 \mathrm{GPa}$, the average value comparison increases the confidence of the solutions being in accordance with each other. Also, the autoclaved specimens were on average $20 \%$ stiffer in the $90^{\circ}$ direction than the OoA specimens, which follows the trend determined from experimental testing in the $0^{\circ}$ direction almost exactly.

\subsection{Numerical Comparison}

The average measured values for Modulus are used in the numerical solution. Due to negligible differences between the two test conditions, the autoclaved specimens average is used to reduce discrepancy between the numerical solution and the theoretical solution calculated using CLT. Strain measurements were extracted from each of the elastic tests for comparison with the numerical solution calculated in ABAQUS, which can be seen in Appendix C. Using MATLAB, data points were indexed by their proximity to the $5 \mathrm{kN}$ load value that the strain measurements are compared. The corresponding strain measurement was taken from the strain measurement data and imported into a Microsoft Excel document. All the strain measurements were then compared to the value calculated in ABAQUS, which is $-0.000649262 \mathrm{~mm} / \mathrm{mm}$. 
Considering the BlueHill software is programmed specifically for a compression test, all the compressive strain measurements are recorded as positive values even though they are negative. For this reason, the strain measurements are compared to the absolute value of the numerical solution, and the measured values are on average $32.5 \%$ different than the numerical solution. However, when the two most extreme outliers in each test condition are ignored, the error decreases to only $4.8 \%$. Table 5.4 lists all the compared e11 values with the ignored extreme outliers denoted with strikethrough text.

The discrepancy between the measured strain values and numerical solution can be explained by multiple factors. First, the CAD model used in the numerical solution is modeled from the average height, thickness, and diameter values from the entire specimen population. The discrepancy would most likely be smaller if ten separate simulations were conducted each with an exact CAD representation of the respective tube. Also, each strain measurement may not be the exact value corresponding to a $5 \mathrm{kN}$ load because the BlueHill DAQ system is only programmed to record data every 0.15 secs. Considering the elastic testing is analyzing the linear elastic region, the steep slope of the load-extension curve can skip over the $5 \mathrm{kN}$ value in a fraction of a second and the indexed load values can be anywhere from 10-20N away from $5 \mathrm{kN}$. Also, the average autoclaved modulus values are used in the numerical solution, which creates error between the numerical solution and the OoA strain measurements. 
Table 5.3 Comparison of the Experimental and Numerical e11 Values.

\begin{tabular}{|c|c|c|c|}
\hline Tube Number & $\begin{array}{c}\text { Measured Strain Value } \\
{[\mathbf{m m} / \mathbf{m m}]}\end{array}$ & $\begin{array}{c}\text { e11 Numerical } \\
{[\mathbf{m m} / \mathbf{m m}]}\end{array}$ & \% Difference \\
\hline 4 & 0.00038 & 0.000649262 & 41.472 \\
\hline$z$ & 0.00024 & 0.000649262 & 63.034 \\
\hline 3 & 0.00048 & 0.000649262 & 26.069 \\
\hline 5 & 0.00067 & 0.000649262 & -3.194 \\
\hline 6 & 0.00048 & 0.000649262 & 26.069 \\
\hline 7 & 0.00007 & 0.000649262 & 89.218 \\
\hline 8 & 0.00016 & 0.000649262 & 75.356 \\
\hline 9 & 0.00089 & 0.000649262 & -37.078 \\
\hline 10 & 0.00057 & 0.000649262 & 12.208 \\
\hline Average & 0.000618 & 0.000649262 & 4.815 \\
\hline
\end{tabular}

\subsection{Sources of Error}

There are several recognized sources of error that may contribute to non-corroborating results between the experimental, theoretical, and numerical solutions of this project. First, manufacturing defects in the tube specimens can possibly skew experimental results. These defects include but are not limited to slight ply misalignment during the layup process and miniscule wrinkles or indentations cured into the final specimens. As pictured in Figure 5.11, the wrinkles and indentations are most likely a product of the vacuum bagging method, but they also can be attributed to the quality of the material being used. For instance, the material used in this experiment expired on March 10, 2016 and was not stored properly prior to usage in this project. Aside from being expired, the material selected for this project may have attributed to slightly deficient autoclaved specimens. Because an OoA prepreg was chosen for both test conditions, the increased compaction pressure during the autoclave cure cycle may have forced too much resin through the EVaC's in the prepreg. If too much resin bleeds through the system during cure, the final cured part may experience decreased strength due to an imbalanced fiber volume ratio [25]. Also, the manufacturing techniques that are recommended by TenCate, mainly the 
debulking procedure during the layup process, were unable to be adhered to in the attempt to mitigate further ply wrinkling.

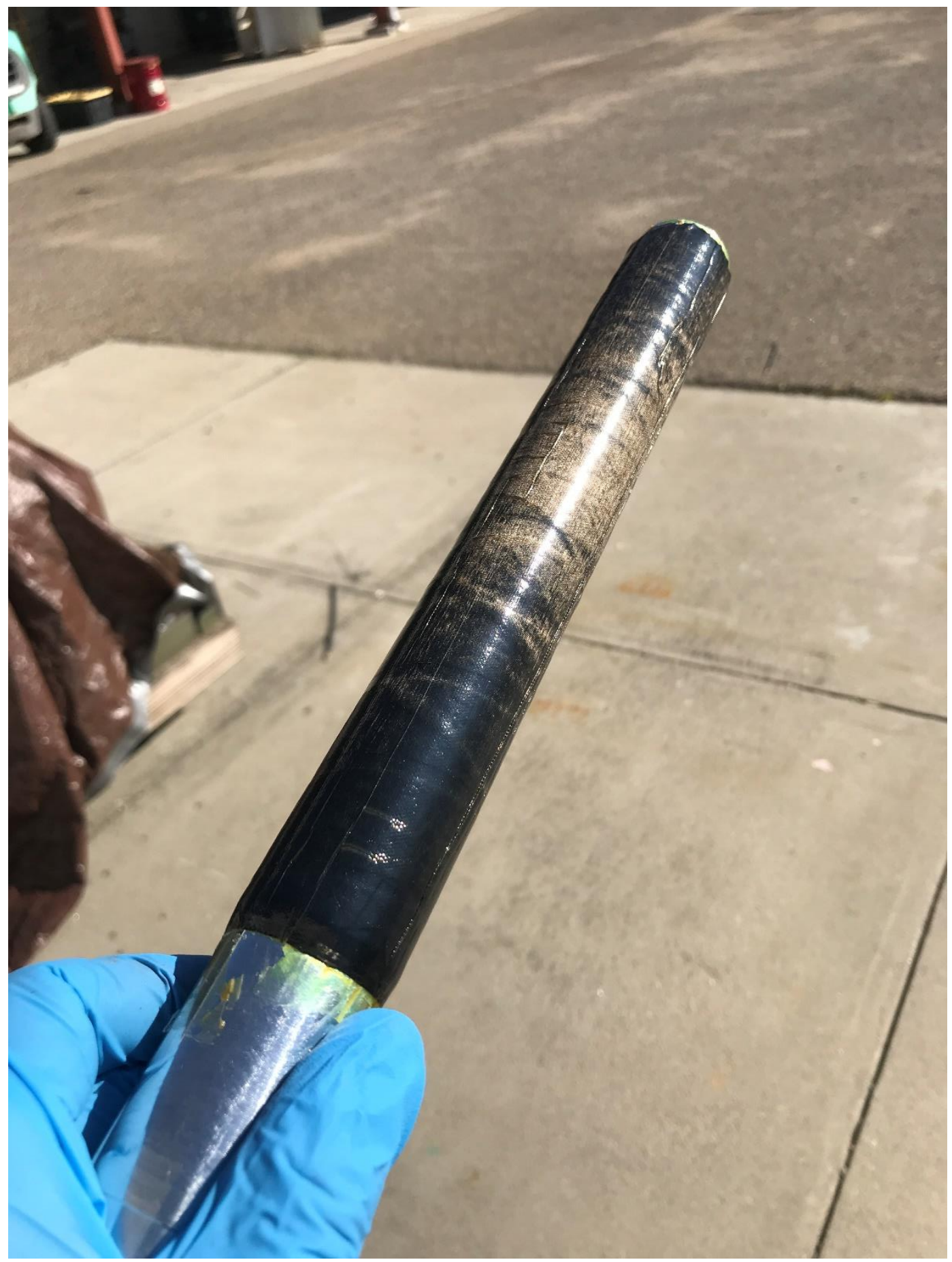

Figure 5.11 Wrinkles Formed in the Final Tubes During the Curing Process. 
Aside from manufacturing defects, factors during the actual mechanical test also may attribute to error and uncertainty in the experimental results. For example, the tubes were chamfered after the top and bottom edges were sanded to be parallel with the loading platens. As seen in Figure 5.12, the parallel edges on some tubes were compromised during the chamfering process. Considering the amount of material removal that occurred during the chamfering process, there was no attempt at further sanding to make the edges parallel with the loading platens. Any further material removal on the top edge would have resulted in drastically changing the specimen geometry and could have possibly compromised the tube wall strength. Another factor during testing that may have skewed results is strain gauge misalignment. Even slight misalignment ( 1-2) of the center gauge and the loading axis will result in error in the experimental results. Finally, microfractures and cracks that may have been introduced to the specimens during the chamfering process and/or elastic testing process can influence the material response to loading; however, these miniscule failures are assumed to be negligible compared to the ultimate strength of the specimen.

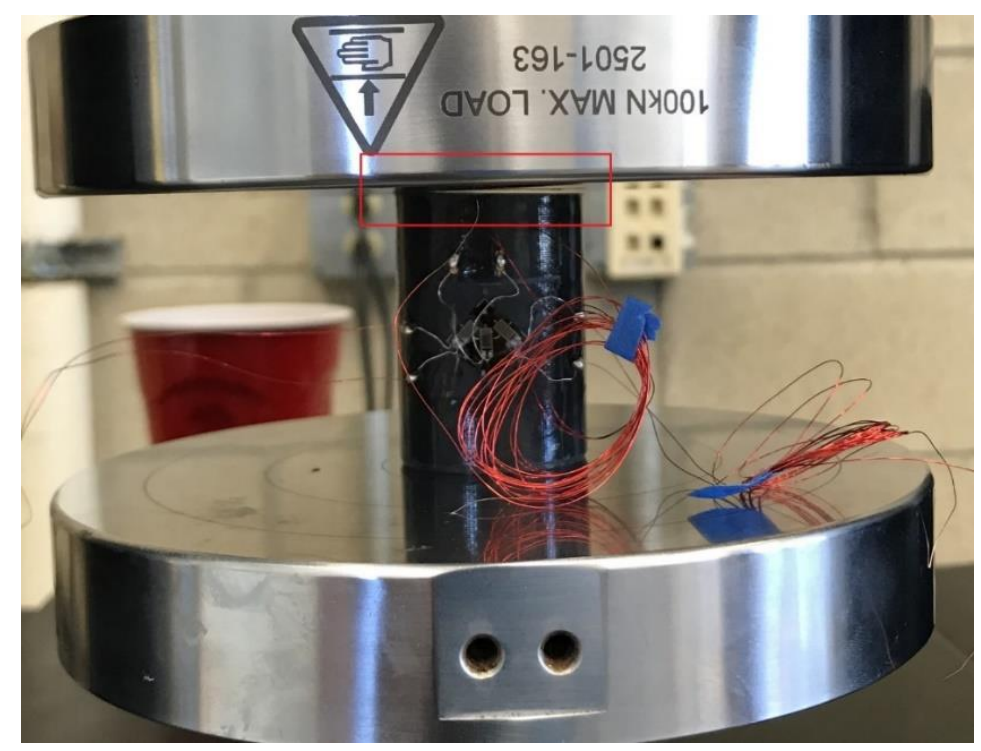

Figure 5.12 Uneven Contact Surfaces on the Top Edge of Tube 7 Observed During Elastic Deformation Testing. 
An overarching source of uncertainty seen during this Thesis involves the loading conditions. As compared to conventional uniaxial tensile testing, uniaxial compression testing introduces buckling into the test specimen. Buckling is an unpredictable mechanical response and can skew results between multiple different tests. Also, with respect to the theoretical and numerical solutions, buckling responses are highly dependent on assumptions and BC's. Slight misrepresentations or assumed phenomena can greatly influence values that are calculated both numerically and theoretically.

To account for the non-automated hand layup of the tube specimens, an uncertainty analysis was conducted to quantify the differences between the geometric properties of the tube specimens. Considering the OD's and heights of the tubes consistently varied to account for the nominal L/D of all the specimens, thickness values were considered. The uncertainty between the thickness of each tube specimens is on the order of $10 \%$. 


\section{CONCLUSIONS}

Throughout the completion of this Thesis, adequate investigation into the manufacturing techniques required to create composite prepreg parts both in- and out-of-autoclave was completed. OoA prepreg final cured part quality is strongly based on process-driven techniques mostly during the layup process, especially debulking procedures to evacuate sufficient amounts of air out of interlaminar pockets in the layup. Using these techniques, thin-walled cylinders were deigned, fabricated, and tested in accordance with a test plan that involved comparisons between experimental, numerical, and theoretical results.

As seen from the Modulus comparison, there is a noticeable difference on the order of $20 \%$ between the OoA and the autoclaved tubes in this study. The autoclave manufacturing process increases the likelihood of a stiffer final part, which can be desirable for some applications. This phenomenon is supported by the maximum load and average load parameters comparison in this study. The autoclaved specimens consistently experienced higher loads before the onset of progressive crushing and resisted the force more than the OoA specimens during progressive crushing. The increased stiffness is likely attributed to decreased void content in the autoclaved specimens that is a function of the increased compaction pressure during the curing process. Air evacuation during layup and cure is essential to achieve a high-quality OoA part [3]. The fact that none of the tubes fabricated for this study were debulked during the layup process suggests a more detrimental reduction in part quality is seen in the OoA specimens as compared to the autoclaved specimens, which are cured at higher pressures. The increased pressure during the cure cycle most likely forces out more air as compared to the lower pressure oven cure, which results in a more void-free final part. 
With the exclusion of a few extreme outliers from manufacturing defects and experimental testing anomalies, the results from experimental testing corroborated the numerical solution within 5\% error. Along with the affirmation that the percent difference of the theoretical comparison for $\mathrm{E}_{11}$ is on the order of $15 \%$ and the percent difference of the theoretical comparison for $\mathrm{E}_{22}$ is on the order of $1.6 \%$, all three solutions (experimental, numerical, and theoretical) are all in accordance with each other.

From a crashworthy energy absorber standpoint, the OoA tubes performed better on both metrics: SEA and CFE. After normalizing the EA by mass, the OoA tubes are observed to have absorbed more energy per unit mass than the stiffer autoclaved counterparts. The increased SEA that the OoA tubes experienced can be attributed to the crushing behavior of the tubes, which is measured by the CFE parameter. The OoA specimens consistently exhibited a CFE closer to the ideal value of 1 than the autoclaved specimens. This phenomenon indicates a more controlled and stable absorption of KE, which makes the OoA specimen better energy absorbers.

The stiffer autoclaved specimens most likely have less interlaminar voids than the OoA specimens and can experience on average higher loads than the OoA specimens. Considering the $11.6 \%$ maximum load drop from the autoclaved specimens to the OoA specimens is not trivial, the OoA specimens cannot be deemed as mechanically efficient as the autoclaved specimens. However, if the application that the energy absorber is being used for can accommodate the decreased loading, the OoA structure is mechanically equivalent if not better from an EA standpoint. In summary, the major conclusions of this Thesis research are:

1. OoA composite prepreg parts are more susceptible to larger discrepancies (on the scale of $16 \%$ ) in final part quality and mechanical responses than autoclaved parts based on process-driven manufacturing techniques. 
2. Curing composite prepreg in the autoclave created $22 \%$ stiffer and more rigid final parts.

3. Despite the differences in final part quality, OoA composite prepreg parts can be up to $6.5 \%$ more efficient than autoclaved parts in certain applications due to other qualities they possess, like their controlled manner of progressive crushing. 


\section{REFERENCES}

[1] Kellas S., Lerch B., and Wilmoth N. Mechanical Characterization of In- and Out-ofAutoclave Cured Composite Panels for Large Launch Vehicles. NASA Langley Research Center. Hampton, Virginia, USA. 2018.

https://ntrs.nasa.gov/archive/nasa/casi.ntrs.nasa.gov/20120009342.pdf

[2] Dang C., Bernetich K., Carter E., and Butler G. Mechanical Comparison of Out-of-Autoclave Prepreg Part to Conventional Autoclave Prepreg Part. Boeing Research and Technology Rotorcraft Systems. Philadelphia, PA, USA. Presented at the American Helicopter Society $67^{\text {th }}$ Annual Forum in Virginia Beach, VA, USA. 2011.

[3] Kourkoutsaki T., Comas-Cardona S., Binetruy C., Upadhyay R.K., and Hinterhoelzl R. The impact of air evacuation on the impregnation time of Out-of-Autoclave prepregs. Composites Part A: Applied Science and Manufacturing, Vol. 79, December 2015, pp. 30-42.

[4] Hughes S.M. and Hubert P. Out-of-Autoclave Prepreg Processing: Effect of Integrated Geometrical Features on Part Quality. SAMPE Tech Wichita, Wichita, KS. Oct, 2013.

[5] Kay J. and Fernlund G. Processing Conditions and Voids in Out-of-Autoclave Prepregs. Department of Materials Engineering, The University of British Columbia. Vancouver, BC. SAMPE Journal, 2012.

[6] Sutter J.K., Kenner W.S., Pelham L., Miller S.G., Polis D.L., Nailadi C., Hou T.H., Quade D.J., Lerch B.A., Lort R.D., Zimmerman T.J., Walker J., and Fikes J. Comparison of Autoclave and Out-of-Autoclave Composites. NASA Glenn Research Center. Cleveland, Ohio, USA. https://ntrs.nasa.gov/archive/nasa/casi.ntrs.nasa.gov/20110016095.pdf

[7] Cauberghs, Julien. Out-of-Autoclave Manufacturing of Aerospace Representative Parts. Thesis submitted to McGill University. Montreal, CA. Jul 2011. http://digitool.library.mcgill.ca/webclient/StreamGate?folder_id=0\&dvs=1567536410664 684

[8] Gardiner, G. Out-of-Autoclave prepregs: Hype of revolution? CompositesWorld. 1 Jan 2011. https://www.compositesworld.com/articles/out-of-autoclave-prepregs-hype-or-revolution. Accessed 27 Dec 2018.

[9] Harte A.M., Fleck N.A., and Ashby M.F. Energy Absorption of Foam-Filled Circular Tubes with Braided Composite Walls. European Journal of Mechanics - A/Solids, Vol. 19, Issue 1, January 2000, pp. 31-50.

[10] Hou T., Pearce G.M.K., Prusty B.G., Kelly D.W., and Thomson R.S. Pressurized composite tubes as variable load energy absorbers, Composite Structures, Vol. 120, February 2015, pp. 346-357. 
[11] Zhu G., Sun G., Liu Q., Li G., and Li Q. On crushing characteristics of different configurations of metal-composites hybrid tubes, Composite Structures, Vol. 175, September 2017, pp. 58-69.

[12] Zhang Z., Sun W., Zhao Y., and Hou S. Crashworthiness of different composite tubes by experiments and simulations, Composites Part B: Engineering, Vol. 143, 15 June 2018, pp. 5695.

[13] Zhang Z., Hou S., Liu Q., and Han X. Winding orientation optimization design of composite tubes based on quasi-static and dynamic experiments, Thin-Walled Structures, Vol. 127, June 2018, pp. 425-433.

[14] Mahdi E., Hamouda A.M.S., and Sebaey T.A. The effect of fiber orientation on the energy absorption capability of axially crushed composite tubes, Materials \& Design (1980-2015), Vol. 56, April 2014, pp. 923-928.

[15] Cender T.A., Gangloff Jr. J.J., Simacek P., and Advani S.G. Void Reduction During Out-ofAutoclave Thermoset Prepreg Composite Processing. Presented at SAMPE Seattle, June 2014.

[16] Fischtziur, Elizabeth. "'Grand-Scale' Autoclave for Boeing's Biggest Wings Nears Completion." Boeing, 16 June 2015, www.boeing.com/company/about-bca/washington/grandscale-autoclave-for-boeing-s-biggest-wings-nears-completion-06-16-2015.page.

[17] Centea T., Grunenfelder L.K., and Nutt S.R. A Review of out-of-autoclave prepregs Material properties, process phenomena, and manufacturing considerations, Composites Part A: Applied Science and Manufacturing, Vol. 70, March 2015, pp. 132-154.

[18] Loos A.C. and Springer G.S. Curing of Epoxy Matrix Composites, Journal of Composite Materials, Vol. 17, Issue 2, March 1983, pp. 135-169.

[19] Epoxy Technology. Cure Matters: Determining the Proper Cure Schedule. Cure Matters: Determining the Proper Cure Schedule, EPO-TEK, 2015, www.epotek.com/site/technicalmaterial-brochure/index.php?option=com_content \&view=article\&id=194\%3Acure-mattersbrochure.

[20] Epoxy Technology. Tg - Glass Transition Temperature for Epoxies. Tg - Glass Transition Temperature for Epoxies, EPO-Tek, 2012, www.epotek.com/site/files/Techtips/pdfs/tip23.pdf.

[21] Kim J.S., Yoon H.J., and Shin K.B. A Study on Crushing Behaviors of Composite Circular Tubes with Different Reinforcing Fibers, International Journal of Impact Engineering, Vol. 38, Issue 4, April 2011, pp. 198-207.

[22] Siromani D., Awerbuch J., and Tan T.M. Finite element modeling of the crushing behavior of thin-walled CFRP tubes under axial compression, Composites Part B: Engineering, Vol. 64, August 2014, pp. 50-58. 
[23] Jones, Robert M. Mechanics of Composite Materials. Hemisphere Publishing Corporation, 1975.

[24] Meredith J., Bilson E., Powe R., Collings E., and Kirwan K. A performance versus cost analysis of prepreg carbon fibre epoxy energy absorption structures, Composite Structures, Vol. 124, June 2015, pp. 206-213. 


\section{APPENDICES}

\section{A. Stress-Strain Plots from Elastic Deformation Testing}

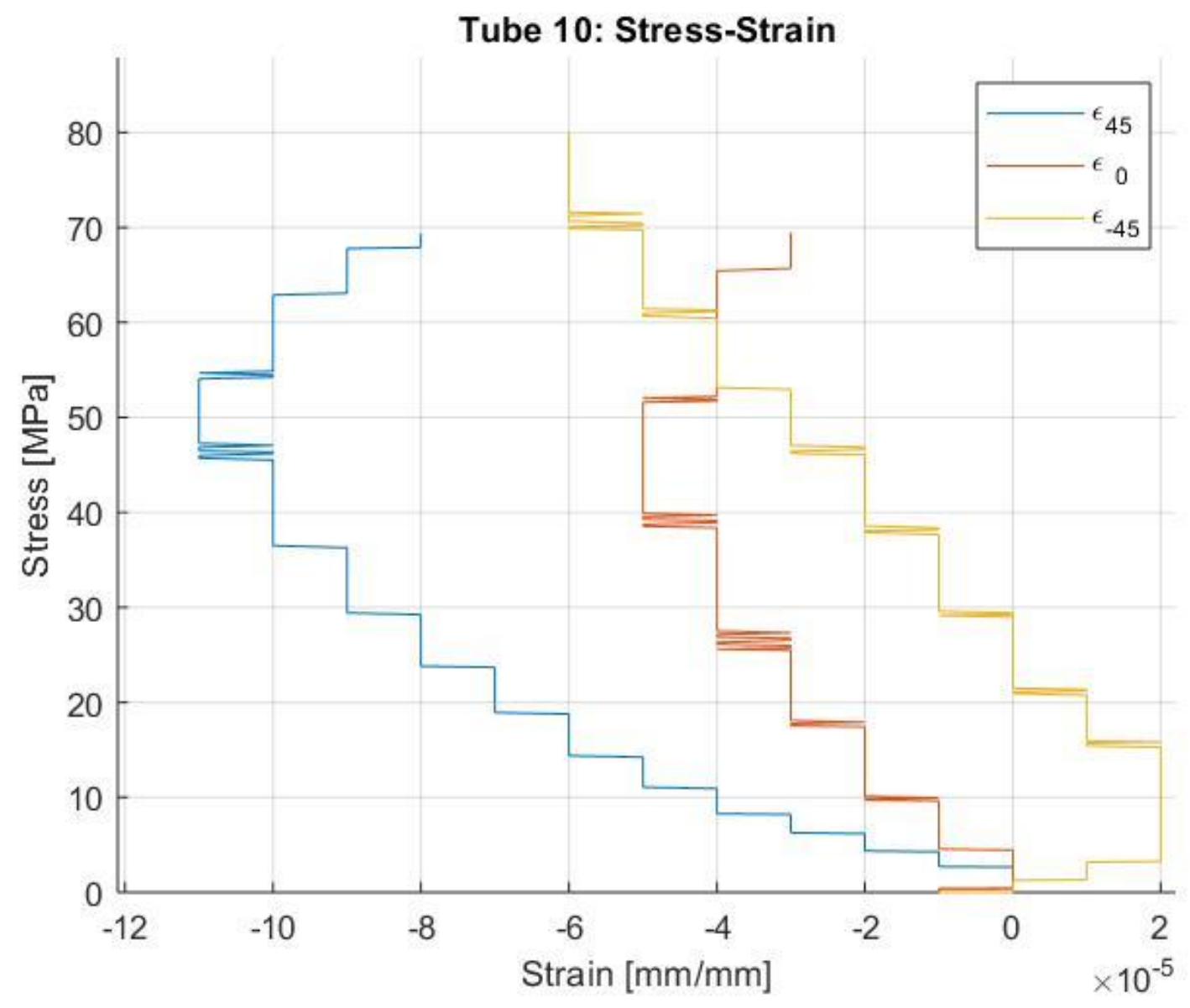

Strain measurements without cotton breather pad 


\section{Tube 10: Stress-Strain}

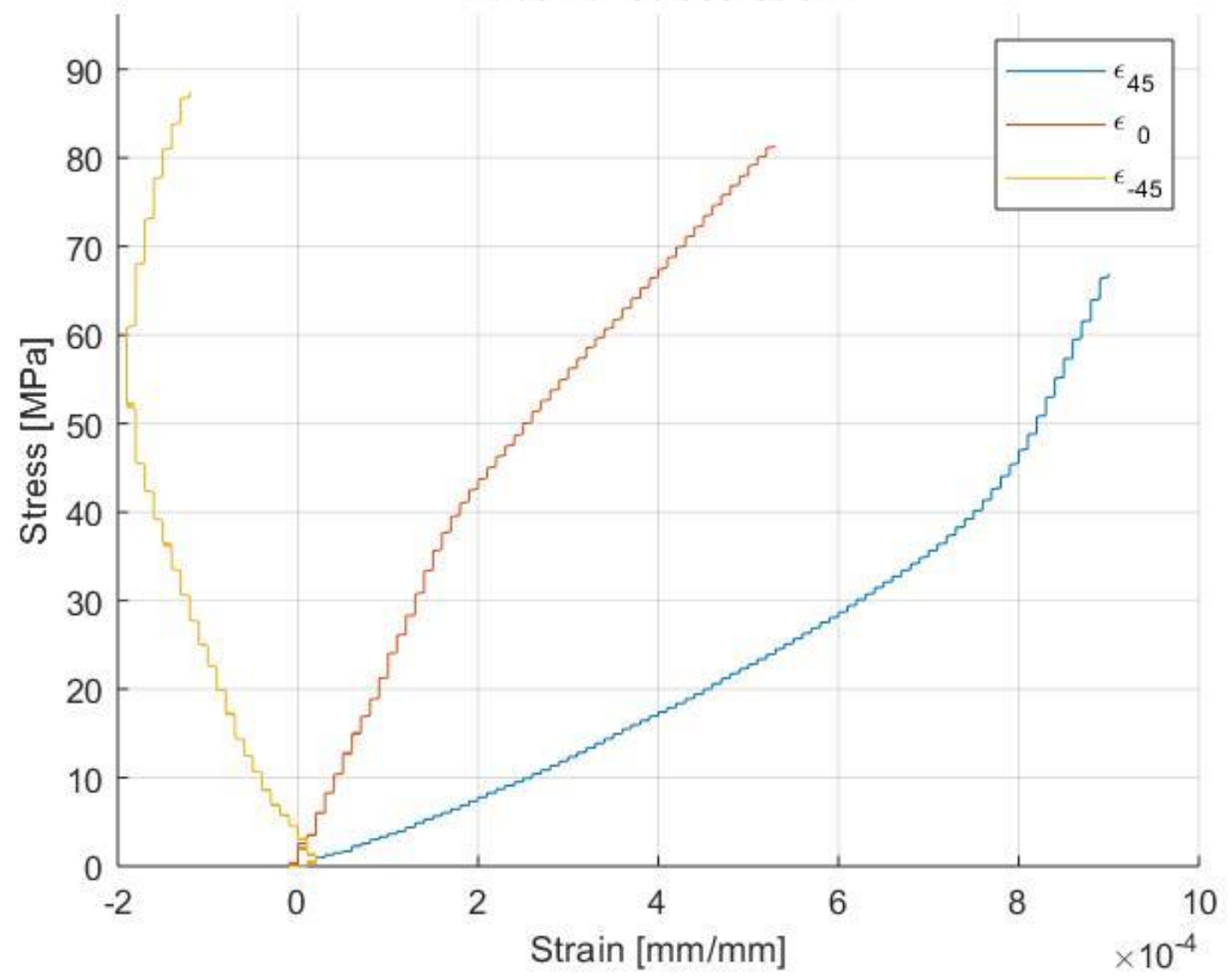

Strain measurements with cotton breather pad 


\section{B. Derivation for Extensional Compliance Matrix from CLT}

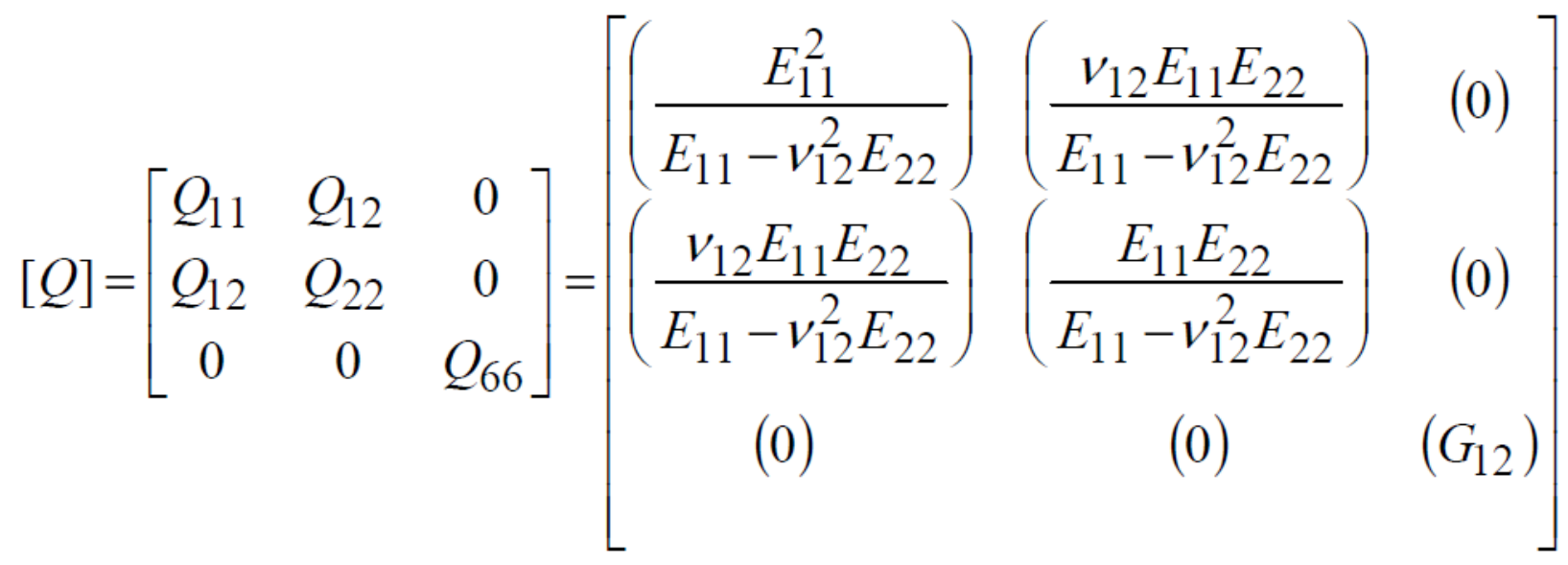

Reduced Stiffness Matrix

$$
\begin{aligned}
& \bar{Q}_{11}=Q_{11} \cos ^{4} \theta+2\left(Q_{12}+2 Q_{66}\right) \cos ^{2} \theta \sin ^{2} \theta+Q_{22} \sin ^{4} \theta \\
& \bar{Q}_{12}=\bar{Q}_{21}=Q_{12}\left(\cos ^{4} \theta+\sin ^{4} \theta\right)+\left(Q_{11}+Q_{22}-4 Q_{66}\right) \cos ^{2} \theta \sin ^{2} \theta \\
& \bar{Q}_{16}=\bar{Q}_{61}=\left(Q_{11}-Q_{12}-2 Q_{66}\right) \cos ^{3} \theta \sin \theta-\left(Q_{22}-Q_{12}-2 Q_{66}\right) \cos \theta \sin ^{3} \theta \\
& \bar{Q}_{22}=Q_{11} \sin ^{4} \theta+2\left(Q_{12}+2 Q_{66}\right) \cos ^{2} \theta \sin ^{2} \theta+Q_{22} \cos ^{4} \theta \\
& \bar{Q}_{26}=\bar{Q}_{62}=\left(Q_{11}-Q_{12}-2 Q_{66}\right) \cos \theta \sin ^{3} \theta-\left(Q_{22}-Q_{12}-2 Q_{66}\right) \cos ^{3} \theta \sin \theta \\
& \bar{Q}_{66}=\left(Q_{11}+Q_{22}-2 Q_{12}-2 Q_{66}\right) \cos ^{2} \theta \sin ^{2} \theta+Q_{66}\left(\cos ^{4} \theta+\sin ^{4} \theta\right)
\end{aligned}
$$

Lamina Stiffness Matrix

$$
A_{i j}=\sum_{k=1}^{n}\left[\left(\overline{\left.Q_{\imath \jmath}\right)}\right]_{k}\left(h_{k}-h_{k-1}\right)\right.
$$

Extensional Stiffness Matrix

$$
\left[A^{*}\right]=[A]^{-1}
$$

Extensional Compliance Matrix 


\section{Numerical Solution - e11 Scalar Plot}

E, E22
SNEG, (fraction = -1.0), Layer = 1
(Avg: $75 \%$ )
\begin{aligned} & \hline$-6.492 \mathrm{e}-04 \\ &$\hline$-6.492 \mathrm{e}-04 \\ &$\hline$-6.492 \mathrm{e}-04 \\ &$\hline$-6.492 \mathrm{e}-04 \\ &$\hline$-6.492 \mathrm{e}-04 \\ &$\hline$-6.492 \mathrm{e}-04 \\ &$\hline$-6.492 \mathrm{e}-04 \\ &$\hline$-6.492 \mathrm{e}-04 \\ &$\hline$-6.493 \mathrm{e}-04 \\ &$\hline$-6.493 \mathrm{e}-04 \\ &-6.493 \mathrm{e}-04 \\ &-6.493 \mathrm{e}-04 \\ &-6.493 \mathrm{e}-04\end{aligned}$
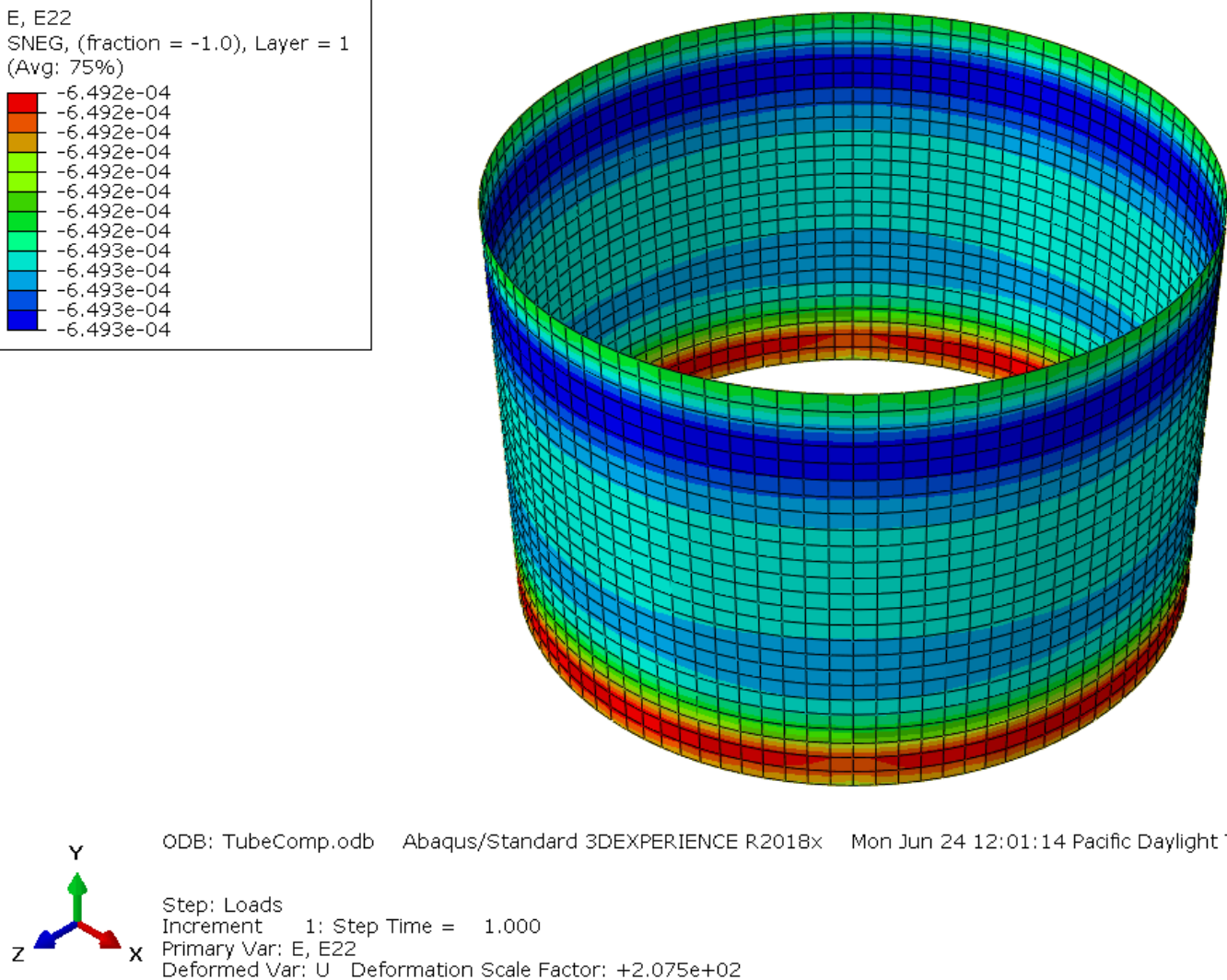

Note: ABAQUS denotes e 22 as the strain in the $0^{\circ}$ direction, but this Thesis denotes e 11 as the strain in the $0^{\circ}$ direction. 